\title{
Estudo viscoelástico de misturas asfálticas frescas e envelhecidas com agregado sinterizado de argila calcinada
}

\author{
Viscoelastic study of fresh and aged hot-mix \\ asphalt with sintered calcined clay aggregate
}

Juliano Rodrigues Spínola ${ }^{1}$, Antônio Cleiton Lopes da Silva ${ }^{1}$, Consuelo Alves da Frota ${ }^{1}$, Hidembergue Ordozgoith da Frota ${ }^{1}$

\footnotetext{
${ }^{1}$ Universidade Federal do Amazonas (UFAM), Grupo de Pesquisa em Geotecnia (GEOTEC), Av. General Rodrigo Octávio Jordão Ramos, 3000, Manaus, AM, Brasil

e-mail: julianospinola10@gmail.com, cleiton.acls@hotmail.com, cafrota@ufam.edu.br,hfrota@ufam.edu.br
}

\begin{abstract}
RESUMO
Os revestimentos asfálticos dos pavimentos flexíveis, em função do ligante betuminoso presente em sua composição, possuem comportamento mecânico dependente de vários fatores, dentre eles: processo de compactação, temperatura e taxa de aplicação de carregamento. Várias são as reações passíveis de ocorrerem nos principais constituintes dessas formulações asfálticas, dentre estas, pode-se citar a oxidação, endurecimento físico e perda de voláteis. No caso do ligante asfáltico, o envelhecimento aumenta a viscosidade, associada a uma diminuição da penetração e alguma perda de suas características aglutinantes. Em particular, o aumento de consistência confere maior dureza com o tempo. No trabalho em pauta, estudou-se o comportamento mecânico de misturas asfálticas confeccionadas com Agregado Sinterizado de Argila Calcinada (ASAC), por meio de ensaios dinâmicos de flexão a quatro pontos. Determinou-se experimentalmente o efeito do processo de compactação dos corpos de prova prismáticos, bem como a influência do envelhecimento do ligante asfáltico no módulo dinâmico $\left|\mathrm{E}^{*}\right|$ da mistura. Constatou-se queda de até 81,1\% no valor do módulo complexo, frente às solicitações de temperatura e frequência selecionadas. Os resultados experimentais foram analisados à luz do modelo de Euler-Bernoulli generalizado para materiais viscoelásticos com carregamento dinâmico representativo do ensaio de flexão a quatro pontos. Salienta-se a compatibilidade do modelo teórico para as duas composições estudadas (fresca e envelhecida), face ao ajuste alcançado, representado pelos coeficientes de determinação $\left(\mathrm{R}^{2}\right)$ resultantes.
\end{abstract}

Palavras-chave: Envelhecimento. Módulo dinâmico. Flexão a quatro pontos. Agregado de Argila Calcinada.

\section{ABSTRACT}

The mechanical behavior of flexible pavement asphalt coatings, composed by bituminous binder, depends on several factors, among them: compaction process, temperature and loading application rate. Several reactions occur on the main constituents of these asphalt mixtures, so as oxidation, physical hardening and loss of volatiles. In the case of the asphalt binder, aging increases viscosity, associated to a decrease in the penetration and loss of its binding properties. In particular, the consistency achieved with the time leads to an increase of the stiffness. This paper aims to study the mechanical behavior of fresh and aged asphalt mixtures manufactured with Sinterized Calcined Clay Aggregate (SCCA) by four-point bending tests. The effect of the compaction process in the prismatic specimens modulus $\left|\mathrm{E}^{*}\right|$ was determined, so as the influence of the asphalt binder aging. The results presented a drop of up to $81.1 \%$ in $\left|\mathrm{E}^{*}\right|$ values under the selected series of temperatures and frequencies. The experimental data was analyzed by means of the Euler-Bernoulli Theory generalized for viscoelastic materials with $4 \mathrm{~PB}$ representative dynamic loading. The theoretical modeling compatibility was pronounced for both searched compositions (fresh and aged), considering the curve fitting achieved, represented by the coefficients of determination $\left(\mathrm{R}^{2}\right)$ that were acquired. 
Keywords: Aging. Dynamic modulus. Four-point bending. Calcined clay aggregate.

\section{INTRODUÇÃO}

Diante do retrospecto deficitário relativo à disponibilidade de jazidas de material pétreo superficial para composição de misturas asfálticas com capacidade suficiente de suporte, observa-se na majoritária porção da região amazônica, os elevados dispêndios com o transporte de tal matéria-prima. Como consequência, destaca-se o notável esforço de pesquisadores na produção e desenvolvimento de estudos em prol da substituição dos agregados graúdos convencionais de misturas asfálticas produzidas a quente pelo agregado sinterizado de argila calcinada (ASAC), como é o caso de FROTA et al. (2006) [1], SILVA et al. (2013) [2], SILVA (2014) [3], Silva et al. (2015a, 2015b) [4, 5], Silva et al. (2016) [6], e mais recentemente, CABRAL (2017) [7] e CUNHA et al. (2018) [8], com o objetivo de se produzir pavimentos asfálticos mecanicamente satisfatórios, bem como oferecer apropriada durabilidade frente às solicitações dinâmicas de tráfego e eventos climáticos.

Nesse contexto, o módulo de rigidez dinâmico sob a ótica da análise mecanicista, apresenta-se como um parâmetro de importância fundamental na formulação de modelos constitutivos de misturas asfálticas, uma vez que busca introduzir princípios de mecânica no projeto de pavimentos, evidenciando sua conotação dúbia que retrata tanto a parcela do comportamento elástico, decorrente dos agregados, quanto o comportamento viscoso, oriundo do ligante asfáltico partícipe de tais composições [9-11]. Neste sentido, CENTOFANTE (2018) et al. [12] assinalam que existe uma gama de estudos que abordam o comportamento viscoelástico linear de ligantes e misturas através de modelos desenvolvidos para capturar os efeitos das taxas de aplicação de carregamento, temperatura e, notadamente, do envelhecimento sobre a resposta mecânica do concreto asfáltico.

Em destaque, assegura-se aos mecanismos de envelhecimento a capacidade de alterar quimicamente a estrutura molecular do ligante asfáltico e, portanto, o desempenho mecânico do compósito como um todo, aumentando a suscetibilidade ao surgimento de manifestações patológicas [13-16]. Por conseguinte, do ponto de vista experimental, atenta-se para a eficiência dos materiais utilizados, evidenciando-se a importância de uma análise detalhadamente concebida para situações que simulem as condições climáticas e de tráfego pelas quais o pavimento será submetido durante sua vida de serviço, bem como ponderar o efeito do envelhecimento sobre suas propriedades.

À luz do exposto, avaliou-se no presente trabalho, como se comporta o módulo dinâmico $\left|\mathrm{E}^{*}\right|$ em vigas constituídas de misturas asfálticas com ASAC em estágio de envelhecimento, bem como o efeito do processo de compactação dos corpos de prova, utilizando-se o ensaio de flexão a quatro pontos. Verificou-se também a aplicabilidade do modelo de flexão de vigas elásticas de Euler-Bernoulli a vigas viscoelásticas em estado fresco e envelhecido, fazendo-se a necessária compatibilização da componente viscosa do Cimento Asfáltico de Petróleo com a frequência de serviço relativo ao modelo correspondente.

\section{FUNDAMENTAÇÃO TEÓRICA}

\subsection{Módulo Complexo $\left|E^{\star}\right|$ de misturas asfálticas e o efeito do envelhecimento sobre suas proprieda- des}

O módulo complexo foi desenvolvido para medir tanto a viscoelasticidade quanto as propriedades elásticas de misturas asfálticas [4, 5, 9]. De acordo com KING (2004) [18], o ensaio de módulo complexo consiste na aplicação de pulsos senoidais de carga, induzindo-se deslocamentos axiais no corpo-de-prova, em que $\sigma 0 \mathrm{e}$ Eo são, respectivamente, as amplitudes de tensão e deformação (equação 1), $\omega$ está associada à frequência de aplicação de carga e $\varphi$ é o ângulo de fase, que representa a defasagem de tempo entre os picos de tensão e deformação, dada a característica viscoelástica do material [17], ilustrados na Figura 1a.

$$
E^{*}=\frac{\sigma(t)}{\varepsilon(t)}=\frac{\sigma_{0}}{\varepsilon_{0}} e^{i \phi}=[\cos \phi+i \operatorname{sen} \phi]=E^{\prime}+i E^{\prime \prime}
$$

Dessa forma, a relação entre a tensão senoidal e a deformação define o módulo complexo (equação 2), constituído pelas componentes da parte real $\left|E^{\prime}\right|$ (equação 3) e imaginária $\left|E^{\prime \prime}\right|$ (equação 4), conhecidas como fração de armazenamento ou módulo elástico, e fração de perda ou módulo viscoso, respectivamente, de acordo com a Figura $1 b$. 


$$
\begin{aligned}
& |\mathbf{E} *|=\left|\sqrt{E^{\prime 2}+E^{\prime \prime 2}}\right| \\
& E^{\prime}=|\mathbf{E} *| \cos \varphi \\
& E^{\prime}=|\mathbf{E} *| \operatorname{sen} \varphi
\end{aligned}
$$
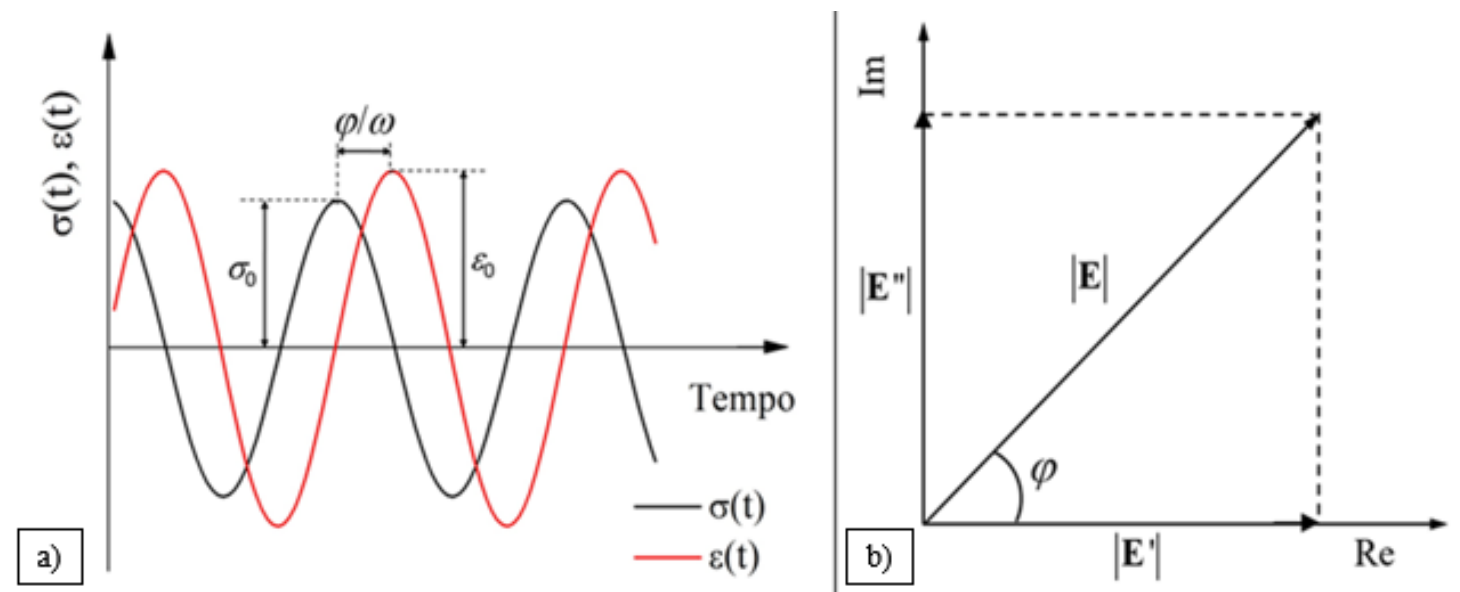

Figura 1: a) Deslocamento da curva de deformação $\varepsilon(\mathrm{t})$ em relação à curva de tensão aplicada $\sigma(\mathrm{t})$, em que se nota uma defasagem temporal $\varphi$. b) Esquema representativo das componentes real $|E ’|$ e imaginária $\left|E^{\prime \prime}\right|$ do módulo complexo.

Nesse sentido, misturas asfálticas submetidas a altas temperaturas tendem a apresentar maiores valores de ângulos de fase e maior suscetibilidade à deformação. Por outro lado, quando a temperatura de serviço é baixa, esses materiais denunciam comportamento elástico, com menores valores de ângulo de fase, capazes de suportar tensões sem sofrer deformações exageradas [19, 20].

Em termos gerais, como o ligante asfáltico é um material viscoelástico, SARSAM \& ADBULMAJEED (2014) [21] relatam que o envelhecimento de pavimentos flexíveis ocorre comumente por oxidação do asfalto e volatilização das moléculas de malteno com baixo peso molecular. Resulta assim, no acréscimo da viscosidade, associado à diminuição da penetração e do ponto de amolecimento. Por conseguinte, esse aumento da consistência influencia o comportamento físico e reológico do material, tornando-o menos flexível e mais quebradiço. Em adição, ANDROJIĆ (2016) [14] esclarece que o envelhecimento decorre de alterações na composição química original do ligante. Essas modificações, segundo SIRIN et al. (2018) [22], transcorrem de processos relacionados ao tempo de usinagem e armazenamento, alusivos ao envelhecimento a curto prazo, juntamente com as condições climáticas e tempo de exposição, no que diz respeito ao mesmo fenômeno, porém a longo prazo.

Corrobora-se, nesse enfoque, com o estudo de FROTA et al. (2006) [1] que obtiveram os parâmetros viscoelásticos de misturas asfálticas compostas com ASAC, envelhecidas em estufa não ventilada e dosadas conforme Metodologia Marshall, por meio de ensaios de creep estático e do ensaio Marshall. Os resultados indicaram que o aumento do envelhecimento resultou no acréscimo da rigidez e da estabilidade Marshall, juntamente com a redução dos valores de deformação. Registra-se ainda, os trabalhos de LOLLY (2013) [23] e CUI et al. (2014) [24]. O primeiro autor examinou o impacto da exposição do ligante asfáltico a altas temperaturas ao longo do tempo. Os resultados correspondentes evidenciaram um elevado crescimento da viscosidade à medida em que se aumenta o tempo de exposição, bem como o desenvolvimento de alterações expressivas de incremento no módulo dinâmico. Os outros autores, por sua vez, analisaram as propriedades de dois tipos de ligantes asfálticos durante processo de volatilização quando submetidos a altas temperaturas. Notou-se que a massa dos fluidos decresce, conquanto se estende o tempo de exposição.

Nesta mesma linha pesquisa, WEN \& WANG (2019) [25] pesquisaram o comportamento do módulo dinâmico de três tipos de misturas asfálticas submetidas a diferentes estágios de envelhecimento, por meio de ensaios uniaxiais. Comprovou-se aumento do $\left|\mathrm{E}^{*}\right|$ à medida em que se acrescia o tempo de envelhecimento. Exemplifica-se, sucintamente, que as misturas do tipo SMA ensaiadas a $20{ }^{\circ} \mathrm{C}$ e $1 \mathrm{~Hz}$, apresentaram valores de $\left|E^{*}\right|$ superiores em $32,5 \%, 43,3 \%, 57,5 \%$ e 70,4\% após envelhecimento de 7, 14, 28 e 42 dias, respectivamente, quando comparados com os corpos de prova em estado fresco. 


\subsection{Teoria de Euler-Bernoulli para vigas viscoelásticas}

Neste estudo, a teoria de Euler-Bernoulli, originalmente desenvolvida para vigas elásticas, será generalizada para introduzir a componente viscosa do ligante asfáltico, com a finalidade de comparar essa teoria com os resultados experimentais a serem obtidos, com o que se determinará os parâmetros físicos do material estudado.

Na Figura 2, apresenta-se o esboço de uma viga prismática submetida a um carregamento dinâmico genérico $q(x, t)$, dependente da coordenada $x$ ao longo da viga e do tempo $t$ de aplicação da força externa, de comprimento 1 e seção transversal retangular uniforme de área $A$ com dimensões $b \times h$ e densidade de massa por unidade de volume $\rho$.

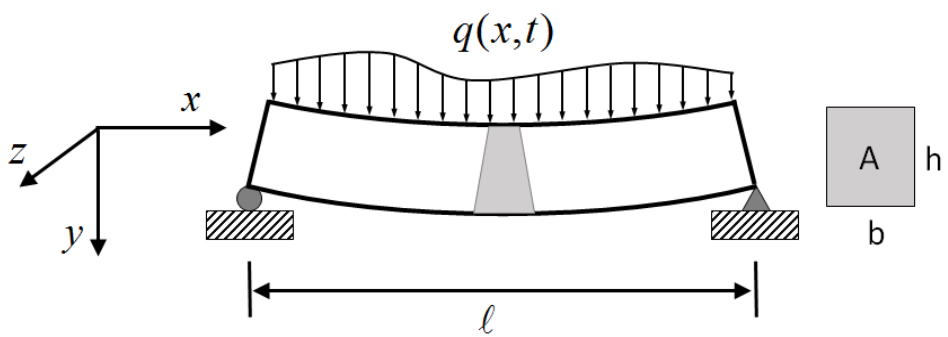

Figura 2: Viga prismática submetida a um carregamento dinâmico genérico $q(x, t)$, de comprimento $l$ e seção transversal retangular de dimensões $b \times h$.

Na Figura 3, mostra-se em detalhes os esforços agindo no trecho hachurado de comprimento infinitesimal $d x$ da viga representada na Figura 7. Nos cálculos a seguir serão empregadas as hipóteses de EulerBernoulli, em que a seção transversal da viga é inicialmente plana e perpendicular à linha elástica, permanecendo assim durante todo o processo de flexão. Por essa razão, o momento de flexão $M$ é escrito em função da curvatura $\partial^{2} \mathrm{y} / \partial \mathrm{x}^{2}$ como:

$$
\frac{\partial^{2} y(x, t)}{\partial x^{2}}=\frac{M}{E I_{z}}
$$

em que y é a coordenada da linha elástica da viga, $E$ é o módulo de elasticidade e $I_{z}$ o momento de inércia da seção transversal da viga em relação ao eixo $z$.
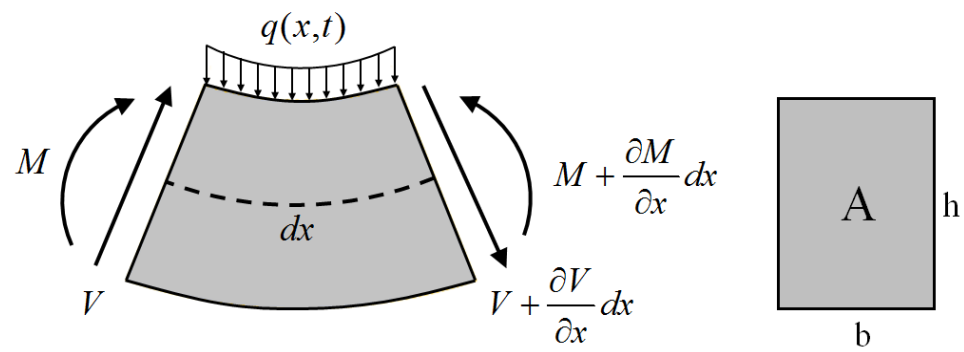

$\mathrm{b}$

Figura 3: Elemento diferencial da viga prismática submetida a um carregamento dinâmico genérico $q(x, t)$, de comprimento $l$ e seção transversal retangular de dimensões $b \times h$.

Do equilíbrio das forças no elemento infinitesimal, obtém-se a equação 6:

$$
-V+\left(V+\frac{\partial V}{\partial x} d x\right)+q(x, t) d x=\rho A d x \frac{\partial^{2} y(x, t)}{\partial t^{2}}
$$

onde, $V$ representa o esforço cisalhante na interface e $\rho$ a densidade volumétrica do material, de maneira que $\rho A d x$ é a massa do elemento diferencial.

Considerando que o esforço cortante $V$ consiste na derivada parcial do momento fletor $M$, das expressões 5 e 6, resulta a equação de Euler-Bernoulli para seção transversal uniforme descrita a seguir: 
$\frac{\partial^{4} y(x, t)}{\partial x^{4}}+\frac{1}{a^{2}} \frac{\partial^{2} y(x, t)}{\partial t^{2}}=\frac{q}{E I_{z}}(x, t)$

onde,

$$
a^{2}=\frac{E I_{z}}{\rho A}
$$

A equação 7 de Euler-Bernoulli aplica-se a materiais elásticos. Entretanto, o material que se estuda na pesquisa em voga, o concreto asfáltico, tem características viscoelásticas. Por essa razão, será introduzida a viscosidade $\gamma$ naquela expressão. Para tanto, utiliza-se o modelo viscoelástico de Kelvin-Voigt representado pela Figura 4, em que uma mola com módulo de elasticidade $E$ é acoplada paralelamente a um amortecedor, com coeficiente de viscosidade $\gamma$.

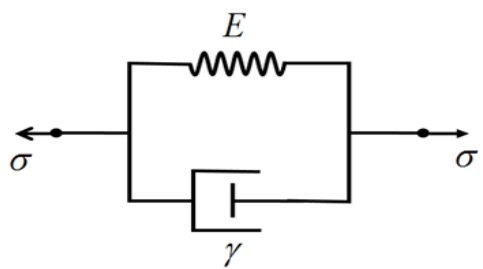

Figura 4: Modelo de Kelvin-Voigt para um sistema viscoelástico representado por uma mola de módulo de elasticidade $E$ acoplada paralelamente a um amortecedor com coeficiente de viscosidade $\gamma$.

Neste sistema, a tensão total é igual à soma das tensões sentidas pela mola e pelo amortecedor, conforme relação denotada na equação 9:

$$
\sigma=\left(E+\gamma \frac{\partial}{\partial t}\right) \varepsilon
$$

Para se obter a Equação de Euler-Bernoulli para materiais viscoelásticos, substitui-se na equação 7 o termo aditivo expresso pelo equação 10 :

$$
E \rightarrow E+\gamma \frac{\partial}{\partial t}
$$

de maneira que aquela equação passa a ser escrita na forma:

$$
E I_{z} \frac{\partial^{4}}{\partial x^{4}} y(x, t)+\gamma I_{z} \frac{\partial^{4}}{\partial x^{4}} \frac{\partial}{\partial t} y(x, t)+\rho A \frac{\partial^{2}}{\partial t^{2}} y(x, t)=q(x, t),
$$

cuja solução será utilizada na análise dos resultados experimentais. Nesse sentido, para determinar a sua solução, realiza-se os seguintes procedimentos:

1) Expande-se $y(x, t)$ nos modos de vibração natural da viga, obtidos a partir das raízes da equação 7 $\operatorname{com} q(x, t)=0$, assim descrita:

$$
y(x, t)=\sum_{n=1}^{\infty} C_{n}(t) Y_{n}(x),
$$

em que $Y_{n}(x)$ é a solução da equação 13:

$$
\frac{\partial^{4} y(x, t)}{\partial x^{4}}+\frac{1}{a^{2}} \frac{\partial^{2} y(x, t)}{\partial t^{2}}=0 .
$$

2) Substitui-se a equação 12 na equação 11 , com o que se obtém: 


$$
\sum_{n=1}^{\infty}\left[\rho A \ddot{C}_{n}(t)+\gamma I_{z} \beta_{n}^{4} \dot{C}_{n}(t)+E I_{z} \beta_{n}^{4} C_{n}(t)\right] Y_{n}(x)=q(x, t)
$$

Sendo,

$$
\beta_{n}=\frac{n \pi}{\ell} \quad(n=1,2,3, \ldots)
$$

3) Multiplica-se a equação 14 por $Y_{n}(x)$ e integra-se ambos os lados em $x$, usando-se as condições de ortogonalidade dos modos normais de vibração da viga, $Y_{n}(x)$, para encontrar:

$$
\ddot{C}_{n}(t)+2 \xi_{n} \beta_{n}^{2} \dot{C}_{n}(t)+a^{2} \beta_{n}^{4} C_{n}(t)=\frac{Q_{n}(t)}{\rho A}
$$

onde,

$$
\begin{aligned}
& \xi_{n}=\frac{\gamma I_{z}}{2 \rho A} \beta_{n}^{2} \\
& Q_{n}(t)=\frac{\ell}{2} \int_{0}^{\ell} Y_{n}(x) q(x, t) d x .
\end{aligned}
$$

4) Toma-se as transformadas de Laplace de ambos os lados da equação 16, obtendo-se:

$$
C_{n}(s)=\frac{1}{s^{2}+2 \xi_{n} \beta_{n}^{2} s+a^{2} \beta_{n}^{4}} \frac{Q_{n}(s)}{\rho A},
$$

onde $C_{n}(s)$ e $Q_{n}(s)$ são as transformadas de Laplace de $C_{n}(t)$ e $Q_{n}(t)$, respectivamente

5) Usando o Teorema da Convolução, determina-se a transformada inversa de Laplace da equação 19, resultando:

$$
C_{n}(t)=\frac{2}{\rho A} \frac{1}{\omega_{n} \sqrt{1-\eta_{n}^{2}}} \int_{0}^{\ell} d u Y_{n}(u) \times \int_{0}^{t} d \tau q(u, \tau) e^{-\eta_{n} \omega_{n}(t-\tau)} \operatorname{sen}\left(\omega_{n} \sqrt{1-\eta_{n}^{2}}(t-\tau)\right)
$$

em que,

$$
\omega_{n}=\left(\frac{n \pi}{\ell}\right)^{2} \sqrt{\frac{E I_{z}}{\rho A}}
$$

que são as frequências angulares dos modos naturais de vibração da viga, e:

$$
\eta_{n}=\frac{\xi_{n}}{a}
$$

6) Substitui-se a equação 20 na equação 12 para se encontrar, finalmente, a solução da equação de Euler-Bernoulli para uma viga prismática viscoelástica, sob um carregamento dinâmico $q(x, t)$, que é dada por:

$$
y(x, t)=\frac{2}{\rho A} \sum_{n=1}^{\infty} \frac{Y_{n}(x)}{\omega_{n} \sqrt{1-\eta_{n}^{2}}} \int_{0}^{\ell} d u Y_{n}(u) \times \int_{0}^{t} d \tau q(u, \tau) e^{-\eta_{n} \omega_{n}(t-\tau)} \operatorname{sen}\left(\omega_{n} \sqrt{1-\eta_{n}^{2}}(t-\tau)\right) .
$$




\subsection{Modelagem teórico-experimental no teste de flexão a quatro pontos}

Na Figura 5, mostra-se um esquema representativo do experimento de flexão a quatro pontos sob um carregamento dinâmico. No aparato experimental, a viga prismática biapoiada, de dimensões conhecidas, é submetida a dois carregamentos pontuais aplicados simetricamente a um terço do comprimento, em relação a cada extremidade, conforme descrito na função da equação 24.

$$
q(x, t)=\frac{q_{0}}{2}\left[\delta\left(x-\frac{\ell}{3}\right)+\delta\left(x-\frac{2 \ell}{3}\right)\right] \operatorname{sen}(\omega t)
$$

Onde, $\delta(x)$ é a função delta de Dirac, $\omega$ é a frequência angular associada à frequência $f$ pela relação $\omega=2 \pi f$, e $t$ é o tempo. Nessas condições, a medida de deformação específica $\varepsilon(t)$ do centro da viga ocorre simultaneamente a aplicação da carga.

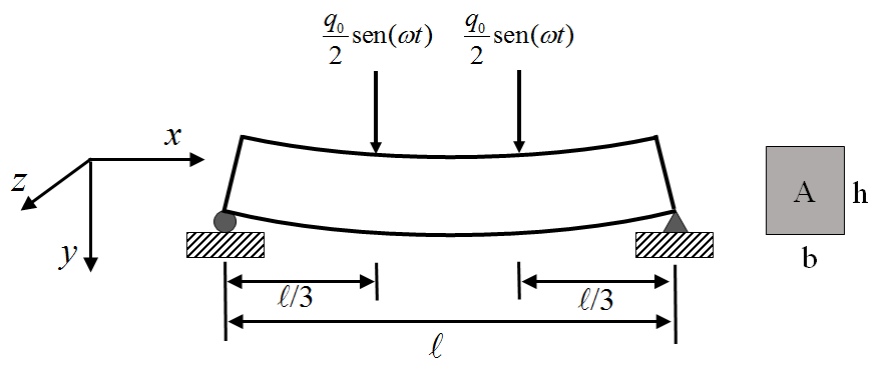

Figura 5: Esquema de esforços representativos do ensaio a flexão a quatro pontos. Aplicam-se duas cargas dinâmicas em um terço do comprimento da viga em relação a cada extremidade. Cada carga tem amplitude $q_{d} / 2$ e varia senoidalmente no tempo com frequência angular $\omega$.

Para se proceder a comparação dos resultados experimentais do ensaio de flexão a quatro pontos com a equação 24, determina-se nesta expressão o valor da deformação no centro da viga, em que $x=l / 2$, para a distribuição de forças empregada naquele ensaio. Realizando-se a integral da equação 23 com $q(x, t)$ dado pela equação 24 , obtém-se:

$$
\begin{aligned}
y(x, t) & =\frac{q_{0}}{\rho A \ell} \sum_{n=1}^{\infty} Y_{n}(x)\left[Y_{n}(\ell / 3)+Y_{n}(2 \ell / 3)\right]\left\{\frac{\operatorname{sen}\left(\omega t-\theta_{n}\right)}{\sqrt{\left(\omega_{n}^{2}-\omega^{2}\right)^{2}+\left(2 \eta_{n} \omega_{n} \omega\right)^{2}}}\right. \\
& \left.-\frac{\omega}{\omega_{n} \sqrt{\left(\omega_{n}^{2}-\omega^{2}\right)^{2}+\left(2 \eta_{n} \omega_{n} \omega\right)^{2}}} \frac{e^{-\eta_{n} t}}{\sqrt{1-\eta_{n}^{2}}} \operatorname{sen}\left(\omega_{n} \sqrt{1-\eta_{n}^{2}} t+\phi_{n}\right)\right\},
\end{aligned}
$$

Em que as fases $\theta_{n}$ e $\phi_{n}$ são dadas respectivamente por:

$$
\begin{aligned}
& \theta_{n}=\tan ^{-1} \frac{2 \eta_{n} \omega_{n} \omega}{\omega_{n}^{2}-\omega^{2}} \\
& \phi_{n}=\tan ^{-1} \frac{2 \eta_{n} \sqrt{1-\eta_{n}^{2}} \omega_{n}^{2}}{2 \eta_{n}^{2} \omega_{n}^{2}-\omega^{2}} .
\end{aligned}
$$

O termo contido na segunda linha da equação 25 , entre as chaves, é transiente, pois decai exponencialmente com o tempo. No limite em que $t \rightarrow \infty$, o sistema encontra-se no estágio estacionário, restando apenas o primeiro termo entre as chaves, descrito na primeira linha. Dessa forma, chega-se a equação 28:

$$
y(x, t)=\frac{q_{0}}{\rho A \ell} \sum_{n=1}^{\infty} \frac{Y_{n}(x)\left[Y_{n}(\ell / 3)+Y_{n}(2 \ell / 3)\right]}{\sqrt{\left(\omega_{n}^{2}-\omega^{2}\right)^{2}+\left(2 \eta_{n} \omega_{n} \omega\right)^{2}}} \operatorname{sen}\left(\omega t-\theta_{n}\right),
$$


com os modos normais de vibração da viga $Y_{n}(x)$ dados por:

$$
Y_{n}(x)=\operatorname{sen}\left(\frac{n \pi x}{\ell}\right)
$$

Sabe-se que o termo $\left[Y_{n}(l / 3)+Y_{n}(2 l / 3)\right]$, posicionado no numerador da equação 28 , varia com $n$ de acordo com a equação 30 .

$$
\left[Y_{6 m \pm 1}\left(\frac{\ell}{3}\right)+Y_{6 m \pm 1}\left(\frac{2 \ell}{3}\right)\right]=(-1)^{m} \sqrt{3}, \quad \text { com } \quad n=6 m \pm 1>0, \quad m=0,1,2,3 \ldots
$$

Verifica-se que os termos de ordens maiores que $n>5$ contribuem de forma irrisória para o somatório da equação 27. Portanto, é razoável considerar apenas o primeiro termo daquela equação, escrevendo:

$$
y(x, t)=\frac{\sqrt{3} q_{0}}{\rho A \ell} \frac{1}{\sqrt{\left(\omega_{1}^{2}-\omega^{2}\right)^{2}+\left(2 \eta_{1} \omega_{1} \omega\right)^{2}}} \operatorname{sen}\left(\omega t-\theta_{1}\right) .
$$

Da equação 31, observa-se que $y(x, t)$ varia senoidalmente com o tempo, com uma defasagem $\theta_{1}$ em relação à força aplicada. Por outro lado, a amplitude de deformação atinge seu valor máximo quando $x=l / 2$. Sabendo-se que $M$ da viga é dada por $\rho A l$, a equação 31 reduz-se a:

$$
y_{\max }=\frac{\sqrt{3} q_{0}}{M} \frac{1}{\sqrt{\left(\omega_{1}^{2}-\omega^{2}\right)^{2}+\left(2 \eta_{1} \omega_{1} \omega\right)^{2}}}
$$

Por outro lado, a força agindo sobre a viga também varia senoidalmente com o tempo, com frequência $\omega$ e valor máximo $F=q_{0}$, que é a sua amplitude. Dividindo-se as amplitudes de deformação e força máximas, a razão é dada por:

$$
\frac{y_{\max }}{F_{\max }}=\frac{\sqrt{3}}{M} \frac{1}{\sqrt{\left(\omega_{1}^{2}-\omega^{2}\right)^{2}+\left(2 \eta_{1} \omega_{1} \omega\right)^{2}}} .
$$

A análise experimental permite concluir que a rigidez varia consideravelmente com a frequência para os corpos de prova de concreto asfáltico, enquanto que para aqueles compostos por materiais como o solo, principal constituinte de subcamadas de pavimentos flexíveis por exemplo, não se verifica tal comportamento. É conhecido que um dos grandes diferenciais entre o solo e o concreto asfáltico é a participação do ligante neste último, o que introduz a contribuição da viscosidade para a sua rigidez, sugerindo-se incorporar ao parâmetro $\eta_{1}$, que está associado à viscosidade, uma dependência em função da frequência, substituindo-se $\eta_{1}$ por $\eta_{1} \omega^{\alpha}$, onde $\alpha$ é o parâmetro a ser ajustado. Dessa forma, a equação 33 passa a ser escrita como:

$$
\frac{y_{\max }}{F_{\max }}=\frac{\sqrt{3}}{M} \frac{1}{\sqrt{\left(\omega_{1}^{2}-\omega^{2}\right)^{2}+\left(2 \eta_{1} \omega_{1} \omega^{1+\alpha}\right)^{2}}} .
$$

Finalmente, a equação 34 será ajustada aos valores experimentais de $y_{\max } / F_{\max }$, de onde se obterá os parâmetros $\omega_{1}, \eta_{1}$ e $\alpha$, que estão associados com o módulo de elasticidade e a viscosidade do concreto asfáltico, de acordo com as equações 17, 21 e 22, na forma:

$$
\begin{aligned}
& \eta_{1}=\frac{1}{2}\left(\frac{\pi}{\ell}\right)^{2} \gamma \sqrt{\frac{I_{z} \ell}{E M}} \\
& \omega_{1}=\left(\frac{\pi}{\ell}\right)^{2} \sqrt{\frac{E I_{z}}{\rho A}} .
\end{aligned}
$$

\section{MATERIAIS E MÉTODOS}

A avaliação do efeito do processo de compactação e do envelhecimento da mistura asfáltica foi realizada 
mediante comparação com os resultados obtidos por [3]. O efeito do processo de compactação se deu com moldagem de corpos de prova com os mesmos parâmetros dos confeccionados anteriormente, variando-se apenas o processo de compactação, consoante a seguir detalhado. Já o envelhecimento foi examinado após repetição dos ensaios, cinco anos após a realização da primeira rodada de testes, dos mesmos corpos de prova, que foram preservados durante esse período de tempo em ambiente com condições climáticas controladas.

\subsection{Nova confecção dos corpos de prova prismáticos e ensaios de módulo de rigidez dinâmico pelo equipamento de flexão a quatro pontos}

Utilizou-se como agregado graúdo o ASAC, material alternativo promissor para composição de concretos asfálticos produzidos na região, amplamente estudado pelo Grupo de Pesquisas em Geotecnia (GEOTEC/UFAM), mostrado na Figura 6a. O agregado miúdo empregado foi a areia comercializada no mercado local (Areia MAO), proveniente de jazidas de areia residual localizadas no território amazonense, notadamente em trechos das estradas BR-174 e AM-070. As granulometrias destes partícipes, consoante Figura 7a, foram manipuladas de modo a compatibilizá-las com aquelas examinadas por [3], objetivando-se a fiel comparação concernente aos resultados de módulo dinâmico. Complementa-se as formulações com o cimento Portland atuando como fíler, e ligante asfáltico do tipo CAP 50/70. Sublinha-se que a dosagem mineral (Tabela 1) e o teor de projeto procederam-se conforme a metodologia Superpave, avaliada por [4], conforme ilustra a Figura 7b. A moldagem e compactação dos corpos de prova prismáticos (Figura 6b) acompanharam, notadamente, os protocolos da EN 12697-24 [26] e o autor citado [3].
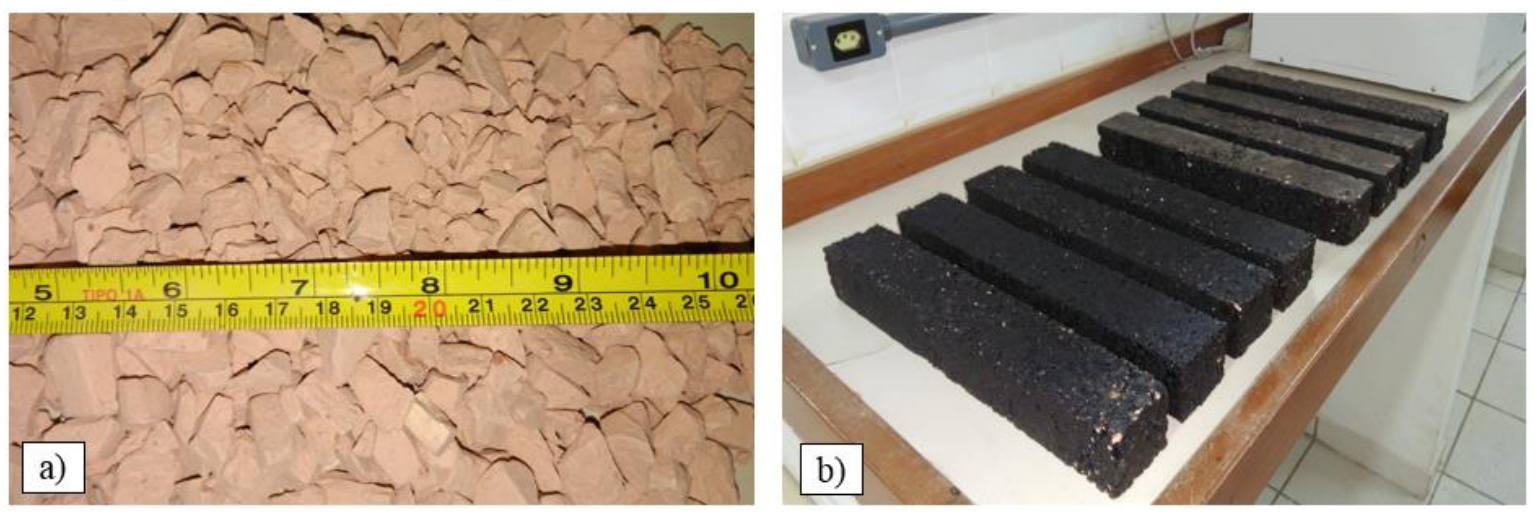

Figura 6: a) Agregado Sinterizado de Argila Calcinada. b) Corpos de prova prismáticos.

Tabela 1: Dosagem mineral empregada na compactação dos corpos de prova prismáticos.

\begin{tabular}{lcccc}
\hline \multirow{2}{*}{ CRITÉRIO (SILVA, 2014) [3] } & \multicolumn{4}{c}{ MATERIAIS CONSTITUINTES } \\
\cline { 2 - 5 } & ASAC & AREIA MAO & CIMENTO PORTLAND & CAP 50/70 \\
\hline Conteúdo em percentual (\%) & 55,24 & 30,29 & 3,56 & 10,90 \\
Conteúdo em massa (g) & $1.311,2$ & 719,1 & 84,6 & 258,7 \\
\hline
\end{tabular}
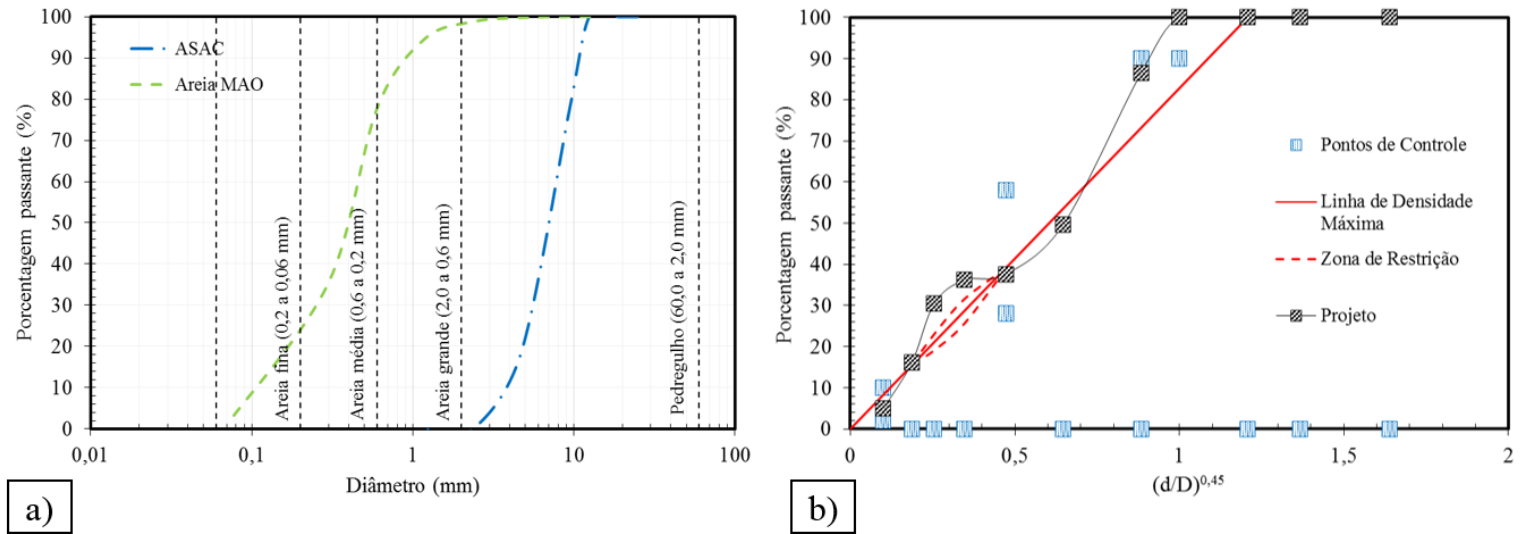
Figura 7: a) Curvas granulométricas dos agregados. b) Compatibilização da mistura asfáltica em estudo com a metodologia Superpave (Adaptado de SILVA, 2014 [3]).

Para realização dos testes mecânicos, o equipamento utilizado foi o Pneumatic Standalone 4 Point Bending, da IPC global, apresentado na Figura 8a. Como o módulo $\left|\mathrm{E}^{*}\right|$ das misturas betuminosas depende da temperatura e das frequências de carregamento, considerou-se temperaturas representativas da área urbana manauense, definindo-as a partir de $25^{\circ} \mathrm{C}$, aumentando-se gradualmente em $5{ }^{\circ} \mathrm{C}$ até $50{ }^{\circ} \mathrm{C}$ [3, 27]. Nesse quesito, toma-se vista ao processo de aferição da temperatura na Figura 8b. Com o intuito de preservar os corpos de prova prismáticos para a sequência dos exames, não ultrapassando 3000 ciclos por carregamento, conduziu-se a série de frequências para as magnitudes de 1, 3, 10, 20 e $1 \mathrm{~Hz}$. A repetição da primeira frequência possibilita examinar se há ou não inferência de danos que prejudiquem a integridade física do corpo de prova por parte do equipamento. Quanto ao modo de carregamento, optou-se por deformação controlada, com amplitude máxima de deformação de $50 \mu \mathrm{m} / \mathrm{m}$, valor que segundo [26], não causa danos ao corpo de prova, permitindo a preservação das vigas para a sequência de ensaios. Esses testes foram realizados tanto nos novos corpos de prova utilizados para análise do efeito da compactação, quanto naqueles compactados há cinco anos, com foco no estudo do efeito do envelhecimento.
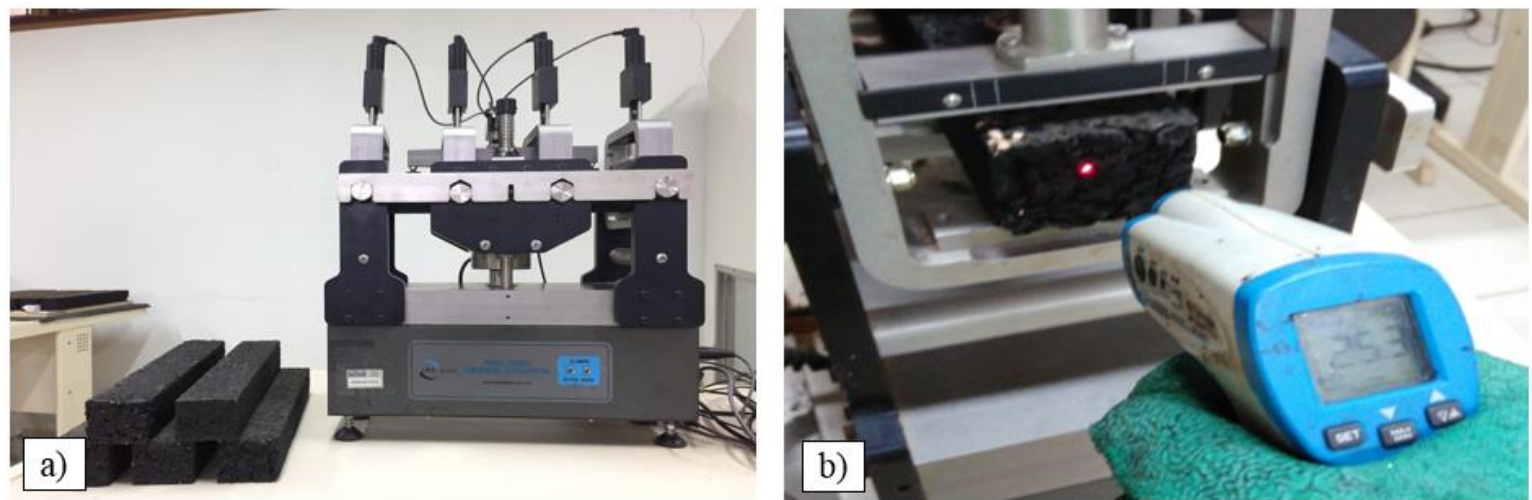

Figura 8: a) Pneumatic Standalone 4 Point Bending Apparatus - GEOTEC; b) Aferição da temperatura com termômetro a laser.

\section{RESULTADOS E DISCUSSÃO}

\subsection{Efeito do tipo de compactação no módulo de rigidez dinâmico $\left|E^{\star}\right|$}

Para a sequência de ensaios, selecionou-se três vigas, observando as que apresentaram resultados com maior proximidade. Considerando os valores médios concernentes às amostras selecionadas para melhor tratamento dos dados obtidos, têm-se os registros dispostos na Tabela 2. Organiza-se igualmente as aferições feitas por [3], na época em que as vigas ainda estavam no estado fresco. Na citada tabela, a nomenclatura "AUTOR (2019)" se refere ao $\left|E^{*}\right|$ das novas vigas compactadas e "SILVA (2014)" àquele das vigas ensaiadas em 2014.

Tabela 2: Resumo do Módulo de Rigidez Dinâmico |E*|, em MPa, para as diversas temperaturas e frequências.

\begin{tabular}{c|c|c|c|c|c|c|c|c}
\hline \multirow{2}{*}{$\begin{array}{c}\text { TEMPERATURA } \\
\left({ }^{\circ} \mathbf{C}\right)\end{array}$} & \multicolumn{2}{|c|}{$\mathbf{1}$} & \multicolumn{2}{|c}{$\mathbf{3}$} & \multicolumn{2}{|c}{$\mathbf{1 0}$} & \multicolumn{2}{c}{$\mathbf{2 0}$} \\
\cline { 2 - 10 } & $\begin{array}{c}\text { AUTOR } \\
\mathbf{( 2 0 1 9 )}\end{array}$ & $\begin{array}{c}\text { SILVA } \\
\mathbf{( 2 0 1 4 )}\end{array}$ & $\begin{array}{c}\text { AUTOR } \\
\mathbf{( 2 0 1 9 )}\end{array}$ & $\begin{array}{c}\text { SILVA } \\
\mathbf{( 2 0 1 4 )}\end{array}$ & $\begin{array}{c}\text { AUTOR } \\
\mathbf{( 2 0 1 9 )}\end{array}$ & $\begin{array}{c}\text { SILVA } \\
\mathbf{( 2 0 1 4 )}\end{array}$ & $\begin{array}{c}\text { AUTOR } \\
(\mathbf{2 0 1 9 )}\end{array}$ & $\begin{array}{c}\text { SILVA } \\
\mathbf{( 2 0 1 4 )}\end{array}$ \\
\hline 25 & 990,3 & $1.302,0$ & $1.124,0$ & $1.608,0$ & $1.311,3$ & $1.953,4$ & $1.429,3$ & $1.998,2$ \\
\hline 30 & 873,0 & $1.048,6$ & $1.094,0$ & $1.312,6$ & $1.245,7$ & $1.649,8$ & $1.404,0$ & $1.776,6$ \\
\hline 35 & 666,3 & 712,6 & 878,7 & 940,4 & $1.108,3$ & $1.211,6$ & $1.238,0$ & $1.268,2$ \\
\hline 40 & 364,0 & 399,6 & 488,7 & 555,4 & 652,3 & 751,8 & 829,3 & 763,4 \\
\hline 45 & 262,7 & 235,4 & 319,7 & 331,4 & 446,7 & 457,4 & 739,0 & 534,0 \\
\hline
\end{tabular}




\begin{tabular}{l|l|l|l|l|l|l|l|l}
50 & 167,3 & 173,6 & 221,7 & 241,8 & 391,0 & 328,6 & 577,7 & 384,6 \\
\hline
\end{tabular}

Investigando contidamente a Tabela 2, constata-se que o módulo de rigidez dinâmico $\left|\mathrm{E}^{*}\right|$ aumenta com a frequência e diminui com o acréscimo de temperatura. Comportamento semelhante foi assinalado por [5], [12] e [25] embora tenham sido empregadas metodologias distintas. Em relação ao estudo de [3], salienta-se a diferença na ordem de grandeza dos valores de módulo de rigidez dinâmico, principalmente quando se confrontam as temperaturas de 25 e $30^{\circ} \mathrm{C}$. As variações pronunciadas são mostradas a seguir, na Tabela 3 , realce para aquelas que superam $200 \mathrm{MPa}$.

Tabela 3: Variação do Módulo de Rigidez Dinâmico |E*|, em MPa, para as diversas temperaturas e frequências.

\begin{tabular}{c|c|c|c|c}
\hline \multirow{2}{*}{ TEMPERATURA $\left({ }^{\circ} \mathbf{C}\right)$} & \multicolumn{4}{|c}{ FREQUÊNCIAS (HZ) } \\
\cline { 2 - 5 } & $\mathbf{1}$ & $\mathbf{3}$ & $\mathbf{1 0}$ & $\mathbf{2 0}$ \\
\hline 25 & 311,7 & 484,0 & 642,1 & 568,9 \\
\hline 30 & 175,6 & 218,6 & 404,1 & 372,6 \\
\hline 35 & 46,3 & 61,7 & 103,3 & 30,2 \\
\hline 40 & 35,6 & 66,7 & 99,5 & 65,9 \\
\hline 50 & 27,3 & 11,7 & 10,7 & 205,0 \\
\hline
\end{tabular}

Na tentativa de compreensão da mudança de comportamento do módulo complexo, as variações apresentadas sugerem que o processo de compactação das vigotas de asfalto consiste num fator de relevante interferência na obtenção do parâmetro. No presente caso, a moldagem dos corpos de prova foi executada em fôrma de aço, por meio de compactação simples em prensa hidráulica marca Bovenau modelo P30 ST 30 toneladas, enquanto que SILVA (2014) [3] optou por prensagem com macaco hidráulico simples, lançando mão de deferir pequenos golpes vibratórios na estrutura do molde para melhor acomodação da mistura asfáltica [4]. Em suma, observa-se que o novo grupo de vigas apresentou módulos de rigidez inferiores. Considerando-se que a variável de controle foi a indução ou não de vibração no processo de compactação, pode-se afirmar que a compactação da massa asfáltica com processo vibratório produz um compósito asfáltico com maior módulo de rigidez que aquele compactado com compactação simples (prensagem contínua e homogênea). Julga-se pertinente informar que a densidade média das vigas pesquisadas recentemente é de $1,71 \mathrm{~g} / \mathrm{cm}^{3}$, conforme Tabela 4, enquanto que a daquelas moldadas em 2014 era 1,84 g/cm³.

Tabela 4: Dados dos corpos de prova moldados para o presente estudo e para o trabalho de SILVA (2014) [3].

\begin{tabular}{c|c|c|c|c|c|c}
\hline \multirow{2}{*}{ CRITÉRIO } & $\begin{array}{c}\text { MASSA } \\
(\mathbf{G})\end{array}$ & $\begin{array}{c}\text { COMPRIMENTO } \\
(\mathbf{M M})\end{array}$ & $\begin{array}{c}\text { LARGURA } \\
(\mathbf{M M})\end{array}$ & $\begin{array}{c}\text { ALTURA } \\
(\mathbf{M M})\end{array}$ & $\begin{array}{c}\text { VOLUME } \\
\left(\mathbf{C M}^{3}\right)\end{array}$ & $\begin{array}{c}\text { DENSIDADE } \\
\left(\mathbf{G} / \mathbf{C M}^{3}\right)\end{array}$ \\
\hline \multirow{2}{*}{$\begin{array}{c}\text { AUTOR } \\
(2019)\end{array}$} & $2.481,40$ & 400 & 64,5 & 56,07 & $1.446,53$ & 1,72 \\
\cline { 2 - 7 } & $2.477,10$ & 400 & 64,5 & 55,63 & $1.435,25$ & 1,73 \\
\cline { 2 - 7 } & $2.458,00$ & 400 & 64,5 & 56,33 & $1.453,31$ & 1,69 \\
\hline \multirow{2}{*}{ MÉDIA } & $2.472,17$ & 400 & 64,5 & 56,01 & $1.445,03$ & 1,71 \\
\hline \multirow{2}{*}{ DESVIO } & 12,46 & 0 & 0 & 0,35 & 9,12 & 0,02 \\
\hline \multirow{2}{*}{ SILVA } & $2.443,00$ & 400 & 64,5 & 51,30 & $1.323,54$ & 1,85 \\
\cline { 2 - 7 }$(2014)$ & $2.461,00$ & 400 & 64,5 & 51,90 & $1.339,02$ & 1,84 \\
\cline { 2 - 7 } & $2.449,00$ & 400 & 64,5 & 51,50 & $1.328,70$ & 1,84 \\
\hline \multirow{2}{*}{ MÉDIA } & $2.451,00$ & 400 & 64,5 & 51,57 & $1.330,42$ & 1,84 \\
\hline \multirow{2}{*}{ DESVIO } & 9,17 & 0 & 0 & 0,31 & 7,88 & 0 \\
\hline
\end{tabular}

Uma possível explicação para esse efeito é o rearranjo da matriz pétrea que, com presença de vibração, tende a apresentar mistura mais densa por ocorrer melhor acomodação das partículas dos agregados. Por outro lado, no processo de compactação simples, ao ocorrer o contato entre as partículas, dado o processo lento 
e uniforme da carga, as mesmas entram em equilíbrio estático e se opõem a tensão vertical aplicada, podendo inclusive sofrer danos a depender da magnitude da carga, o que somado a menor densidade da mistura, reduziriam ainda mais o módulo de rigidez. Sendo assim, para melhor visualização do comportamento mecânico de $\left|E^{*}\right|$, plotou-se o gráfico da Figura 9, de modo a confrontar os resultados publicados pelos pesquisadores. Naquela figura, denominou-se o método de compactação utilizado neste estudo (sem vibração) como "M1" e o método adotado por [3] (com vibração) como "M2".

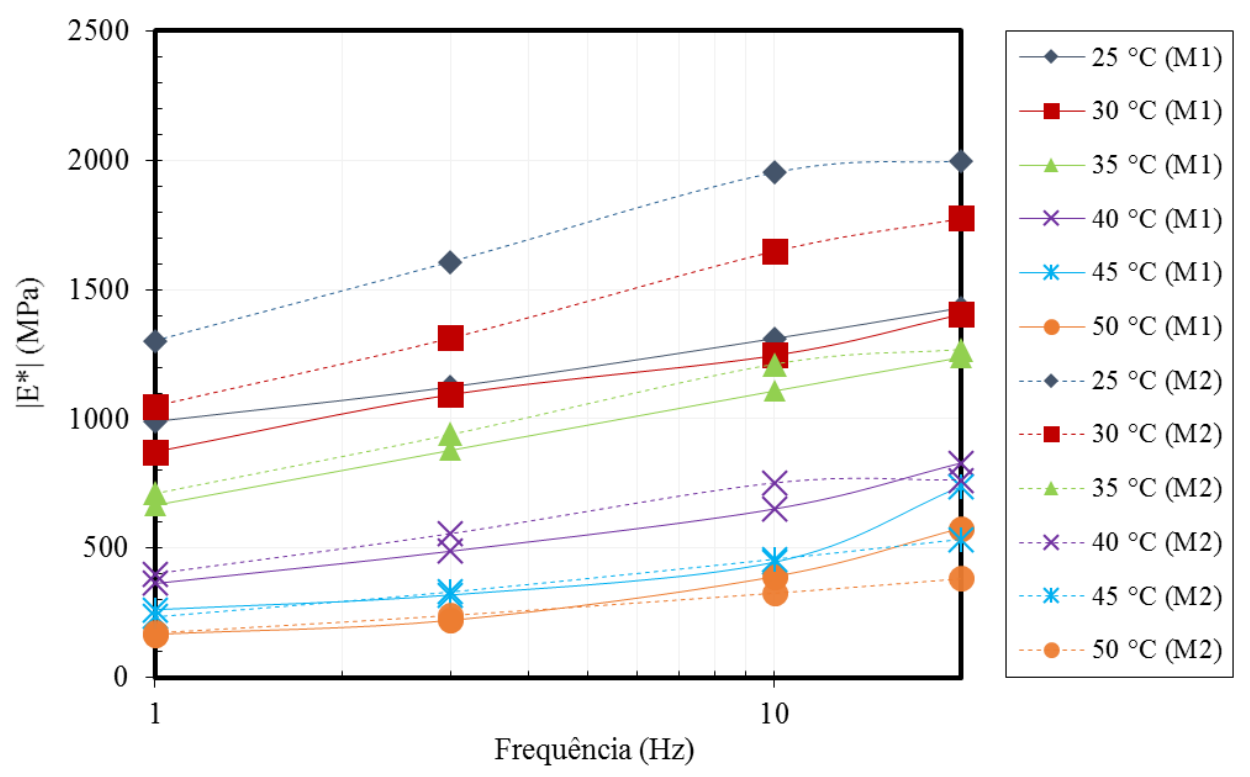

Figura 9: Módulo de rigidez dinâmico $\left|E^{*}\right|$ das vigas recém-moldadas no presente estudo (M1) em comparação com aquelas moldadas em 2014 (M2).

Pelo gráfico supracitado, observa-se uma tendência linear de comportamento até a frequência de $10 \mathrm{~Hz}$, reduzida à medida que se alcança o patamar de $20 \mathrm{~Hz}$, em ambos os cenários. Os resultados contemplados na pesquisa de MELO et al. (2018) [28], na qual reforçaram misturas asfálticas com nanotubos de carbono, compartilham da mesma tendência, embora tenham sido empregados materiais e metodologia distintos, principalmente no que diz respeito aos agregados utilizados e o processo de compactação dos corpos de prova prismáticos. Apesar das diferenças, os autores também obtiveram o $\left|\mathrm{E}^{*}\right|$ por meio do ensaio de flexão a quatro pontos.

Neste sentido, SILVA (2015a) [4] supõe que essa divergência é fruto do tempo de recuperação do material, que deve ocorrer antes da aplicação do pulso de carga seguinte. Nas palavras do autor, se o deslocamento for grande, o tempo de recuperação do material será maior e a frequência deve ser reduzida para que o próximo pulso seja aplicado somente após a recuperação. Caso contrário, o deslocamento deve ser reduzido para que a recuperação ocorra tão rapidamente até o tempo de aplicação do próximo pulso de carga.

Considerando a influência que a taxa de carregamento pode exercer sob a magnitude do módulo $\left|\mathrm{E}^{*}\right|$, CENTOFANTE (2018) et al. [12] explica que a rigidez das misturas asfálticas se associa a um sólido elástico, na qual se observa a herança de propriedades viscoelásticas advindas do ligante nelas contido e, por isso, tornam-se susceptíveis a variações de temperatura e de frequência de aplicação de carga. Dessa forma, KIM (2009) [9] e Di Benedetto (2004) [29] esclarecem que a uma dada temperatura, o concreto asfáltico irá deformar-se lenta e permanentemente se ele for carregado lentamente, ao passo que se o carregamento for aplicado de modo rápido, a rigidez se apresentará maior e a amostra estará sujeita à propagação de trincas. De forma análoga, a uma dada taxa de deformação de carregamento e temperatura definida, o tempo de repouso será suficiente para que a amostra de teste não acumule nenhuma tensão.

\subsection{Efeito do envelhecimento do ligante asfáltico no módulo de rigidez dinâmico $\left|E^{\star}\right|$}

A metodologia utilizada para análise das vigas envelhecidas seguiu o mesmo critério das vigas frescas, mas agora o enfoque será na influência do envelhecimento, notadamente a interação do ligante asfáltico e sua reatividade com o oxigênio, perquirida no escopo deste estudo, condição alcançada mediante a manutenção dos corpos de prova moldados em laboratório, sob condições controladas, desde 2014. A Tabela 5 apresenta 
os valores médios obtidos.

Tabela 5: Resumo do Módulo de Rigidez Dinâmico |E*| das vigas envelhecidas (ENV_2019) e das vigas moldadas em 2014 (RM_2014), em MPa, para as diversas temperaturas e frequências.

\begin{tabular}{c|c|c|c|c|c|c|c|c}
\hline \multirow{2}{*}{$\begin{array}{c}\text { TEMPERATURA } \\
\left({ }^{\circ} \mathbf{C}\right)\end{array}$} & \multicolumn{2}{|c|}{$\mathbf{1}$} & \multicolumn{2}{c}{ 3 } & \multicolumn{2}{c}{$\mathbf{1 0}$} & \multicolumn{2}{c}{$\mathbf{2 0}$} \\
\cline { 2 - 9 } & ENV_2019 & RM_2014 & ENV_2019 & RM_2014 & ENV_2019 & RM_2014 & ENV_2019 & RM_2014 \\
\hline 25 & $2.470,3$ & $1.302,0$ & $2.780,3$ & $1.608,0$ & $2.969,0$ & $1.953,4$ & $3.206,0$ & $1.998,2$ \\
\hline 30 & $1.588,0$ & $1.048,6$ & $1.890,3$ & $1.312,6$ & $2.169,3$ & $1.649,8$ & $2.318,0$ & $1.776,6$ \\
\hline 35 & $1.144,0$ & 712,6 & $1.372,0$ & 940,4 & $1.705,7$ & $1.211,6$ & $1.935,7$ & $1.268,2$ \\
\hline 40 & 976,7 & 399,6 & $1.173,3$ & 555,4 & $1.518,7$ & 751,8 & $1.845,3$ & 763,4 \\
\hline 45 & 610,3 & 235,4 & 829,3 & 331,4 & $1.122,7$ & 457,4 & $1.281,7$ & 534,0 \\
\hline 50 & 524,7 & 173,6 & 754,7 & 241,8 & $1.098,3$ & 328,6 & $1.188,3$ & 384,6 \\
\hline
\end{tabular}

Comparando-se os valores de $\left|E^{*}\right|$ das vigas frescas alusivos ao trabalho de [3] e os envelhecidos ora realizados, que se encontram lado a lado na Tabela 5, observa-se que o decréscimo da rigidez com o aumento da temperatura se mantém, todavia, o efeito do envelhecimento do ligante asfáltico por cinco anos promoveu um acréscimo expressivo na magnitude do módulo $\left|\mathrm{E}^{*}\right|$ característico das misturas com ASAC, conforme análise visual do gráfico da Figura 10. Sobressai-se às demais curvas a linha referente à temperatura de $25^{\circ} \mathrm{C}$, em decorrência da ordem de grandeza que auferiu variações percentuais aproximadas de 47,3; 42,2; 34,2 e $37,7 \%$, frente ao módulo perquirido em 2014 para a mesma temperatura.

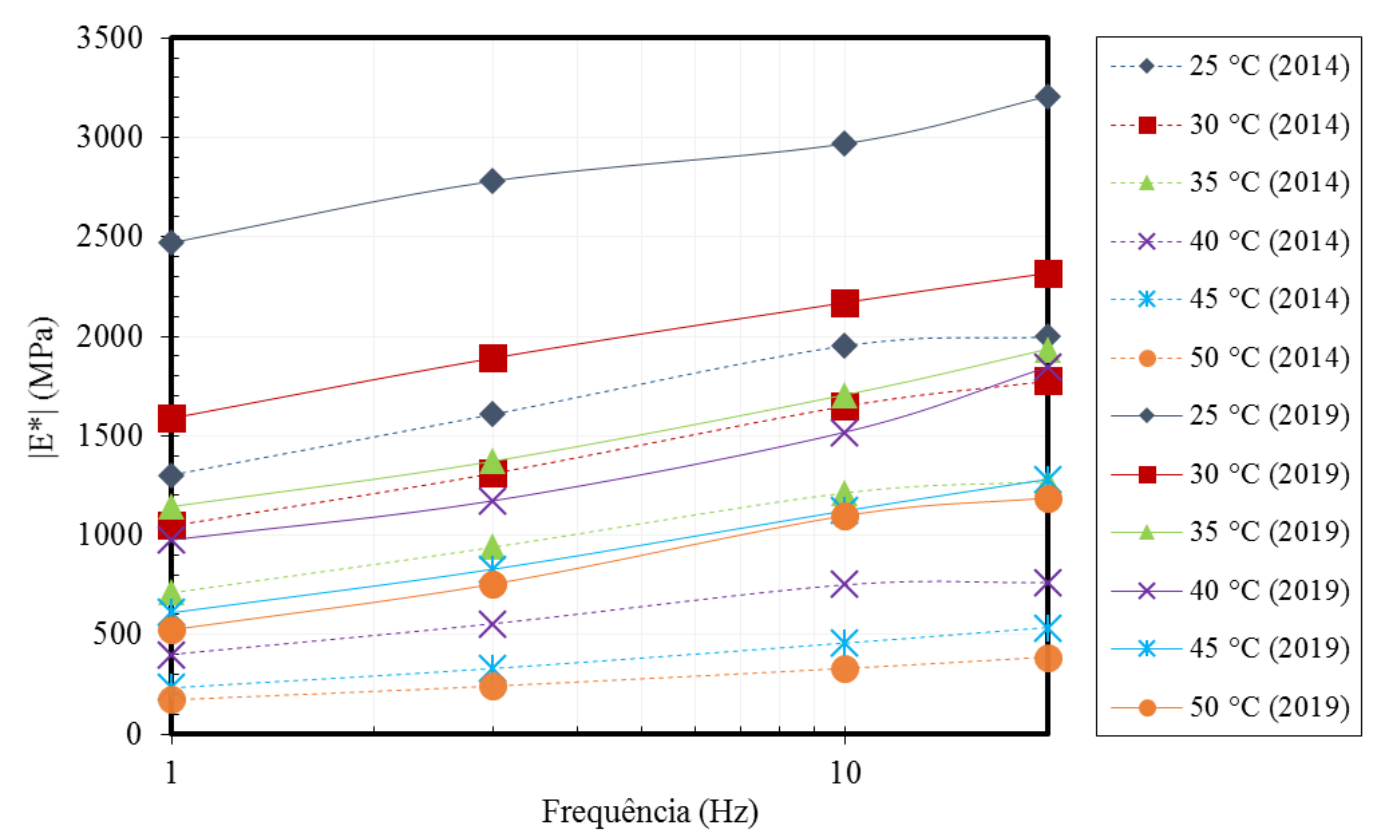

Figura 10: Módulo de rigidez dinâmico $\left|\mathrm{E}^{*}\right|$ das vigas envelhecidas (2019) em comparação com aquelas moldadas em 2014 por SILVA (2014) [3].

Destaca-se também a evolução do parâmetro para as demais temperaturas. Nesse contexto, WEN \& WANG (2019) [25] encontraram disposição similar em seu estudo sobre envelhecimento oxidativo. Exemplifica-se o caso citando que tais autores produziram mistura do tipo SMA que denunciou acréscimo de 75,2\% após 56 dias de envelhecimento. MORENO-NAVARRO et al. (2017) [20] encerra que a viscosidade de li- 
gantes asfálticos depende não só da temperatura, mas é igualmente influenciada por outros fatores, notadamente o conteúdo de asfaltenos e maltenos [30], moléculas constituintes do material. Em decorrência do fenômeno do envelhecimento, que tem início no processo de usinagem e perdura durante toda a vida de serviço do revestimento asfáltico, mormente por sua exposição à variação de temperatura, processo de oxidação e radiação ultravioleta, a relação asfalteno/malteno é alterada, levando ao aumento da viscosidade do ligante, e consequentemente, sua rigidez. O resultado é um compósito mais rígido, com módulo de dinâmico $\left|\mathrm{E}^{*}\right|$ amplificado [31, 32]. Por outro lado, respeitante à variação do módulo dinâmico $\left|E^{*}\right|$ em função da temperatura, denota-se a oscilação das curvas referentes aos compósitos envelhecidos, condição não encontrada no comportamento daqueles moldados em 2014, consoante ilustra a Figura 11. Estas últimas evidenciaram desníveis suavizados.

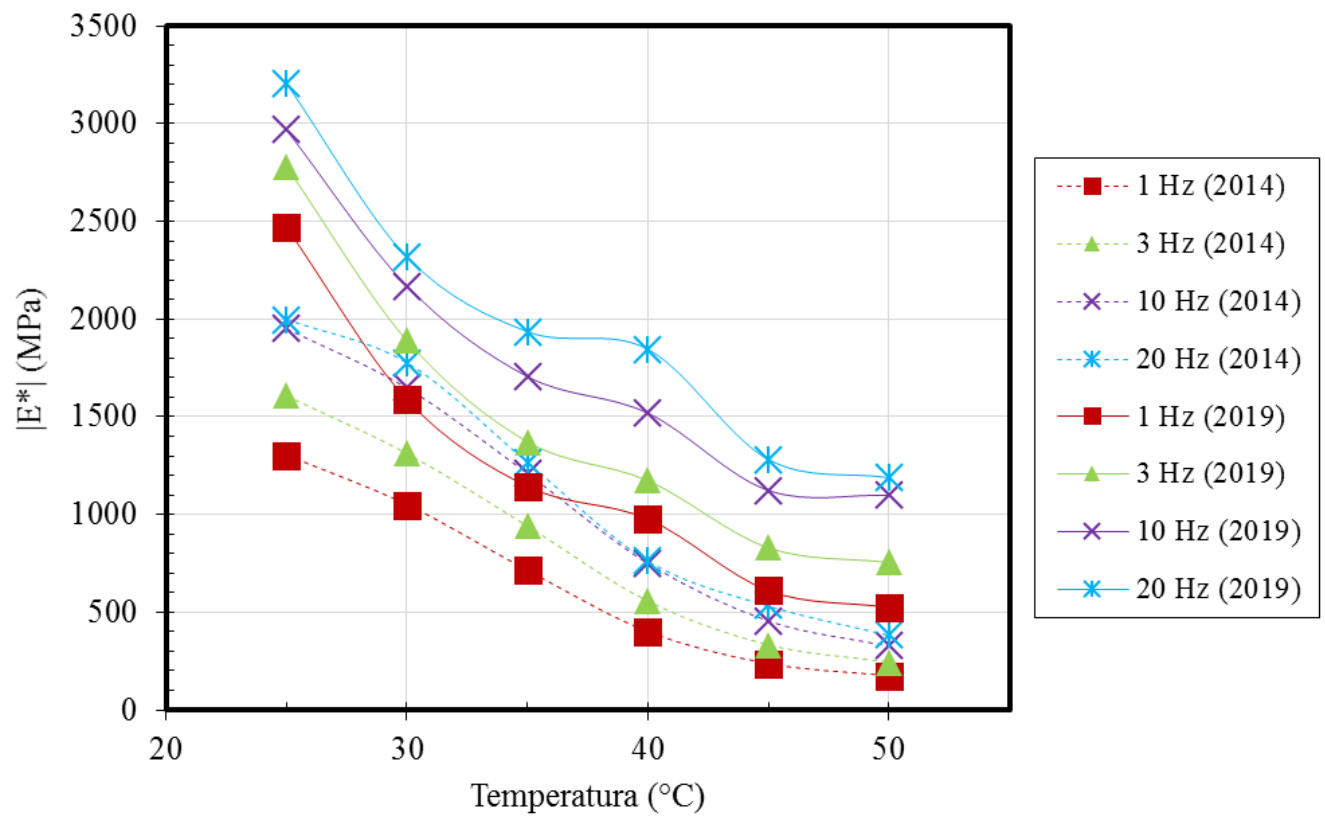

Figura 11: Comparação do módulo de rigidez dinâmico |E*| em função da temperatura, das vigas envelhecidas (2019) comparativamente com as frescas moldadas por [3] em 2014.

Contudo, o comportamento procedeu conforme esperado, onde a rigidez do compósito diminui ao se aquecer os corpos de prova. Ocorre que, em regiões quentes, caso de Manaus, a temperatura média à qual o pavimento asfáltico é submetido, apresenta-se muito superior nos meses mais quentes do ano. Desta feita, face às condições manauaras de temperatura e tráfego, o módulo dinâmico $\left|\mathrm{E}^{*}\right|$ de revestimentos asfálticos com cinco anos de vida útil demonstraria variação de $2.780,3 \mathrm{MPa}\left(25{ }^{\circ} \mathrm{C}, 3 \mathrm{~Hz}\right.$ equivalente a tráfego de $40 \mathrm{~km} / \mathrm{h})$ para $524,7 \mathrm{MPa}\left(50{ }^{\circ} \mathrm{C}, 1 \mathrm{~Hz}\right.$ equivalente a tráfego de $\left.20 \mathrm{~km} / \mathrm{h}\right)$, que corresponde a uma queda de $81,1 \%$, condição que pode estar associada à forte ocorrência de deformação permanente nos revestimentos da cidade [33].

Sob esta perspectiva, KIM (2009) [9] explica que as deformações plásticas podem ser reflexo da capacidade de suporte insuficiente das subcamadas ou do próprio revestimento asfáltico, assim como de ambos simultaneamente. Esse problema se agrava quando o pavimento é submetido a altas temperaturas e/ou lentas taxas de carregamento, pois nessas condições o ligante asfáltico torna-se pouco rígido para suportar a carga e, portanto, o principal tipo de dano é a deformação permanente devido à mudança de volume, em razão de densificação e rearranjo das partículas do agregado causado pelo fluxo de cisalhamento.

De posse dos valores médios de $\left|\mathrm{E}^{*}\right|$, complementou-se a análise com o traçado das curvas mestras características de cada composição, à temperatura de $25^{\circ} \mathrm{C}$ como referência, baseadas no Princípio de Superposição Tempo-Temperatura. Para construir as curvas, foram utilizados os resultados adquiridos para as vigas ensaiadas em 2014 [6] e para as mesmas vigas ensaiadas em 2019, sob condições idênticas de teste, porém decorrido o período de envelhecimento. O comparativo circunda apenas o efeito do envelhecimento, descartando-se qualquer divergência que pudesse fazer alusão ao método de compactação. A seguir, a Figura 12 mostra as curvas mestras dos valores de $\left|E^{*}\right|$ para ambas as composições. Em geral, inspeção visual daquela figura permite observar que o módulo dinâmico cresce em função da frequência e diminui com a temperatura. Isto ocorre tanto para a composição fresca quanto para a composição envelhecida, cujas alterações oriundas 
dos mecanismos de envelhecimento permeiam as modificações na rigidez do compósito, face ao que já foi amplamente discutido.

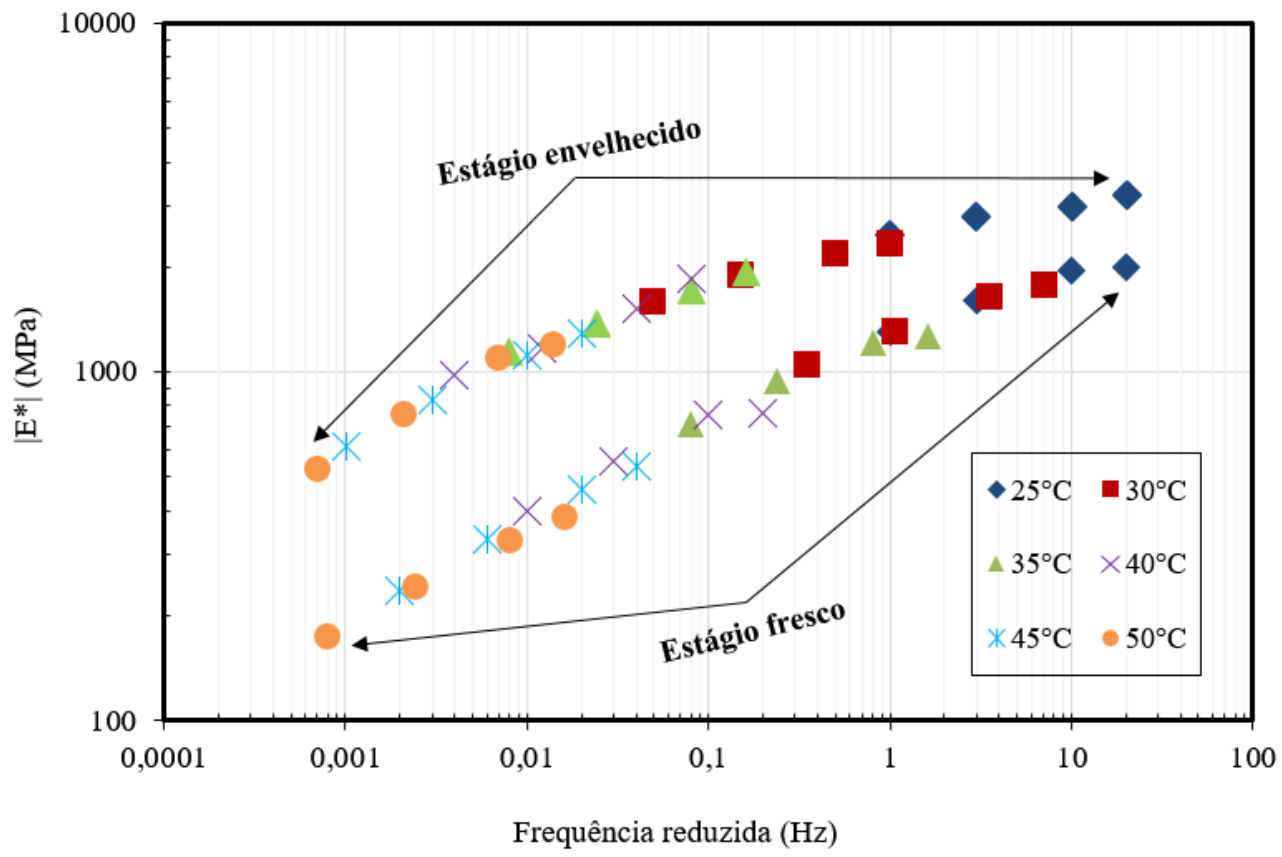

Figura 12: Comparação das curvas mestras para as misturas fresca e envelhecida, à temperatura de $25^{\circ} \mathrm{C}$.

\subsection{Comparação dos resultados experimentais com a Teoria Viscoelástica de Euler-Bernoulli}

As informações referentes a amplitude de deslocamento e a amplitude de força máximas foram retiradas diretamente do software do equipamento 4PB, responsável pela geração automática de relatório disponibilizado para cada frequência de carregamento induzida. O procedimento de ajuste gráfico foi efetuado com auxílio do Lab Fit Curve Fitting Software V 7.2.50. Os resultados obtidos para os parâmetros de ajuste da equação 34 , perquiridos para as vigas recém-moldadas e envelhecidas submetidas às diversas solicitações de temperatura, estão organizados nas Tabelas 6 e 7, respectivamente.

Tabela 6: Parâmetros de ajuste das vigas frescas para as diversas temperaturas.

\begin{tabular}{c|c|c|c|c}
\hline \multirow{2}{*}{ TEMPERATURA $\left({ }^{\circ} \mathbf{C}\right)$} & \multicolumn{4}{|c}{ PARÂMETRO } \\
\cline { 2 - 5 } & $\boldsymbol{\omega 1}$ & $\boldsymbol{n 1}$ & $\boldsymbol{\alpha}$ & $\mathbf{R}^{\mathbf{2}}$ \\
\hline 25 & 712,98 & 173,07 & $-0,76$ & 0,999 \\
\hline 30 & 172,11 & $1.289,38$ & $-0,85$ & 0,944 \\
\hline 35 & 139,79 & $1.013,14$ & $-0,77$ & 0,997 \\
\hline 40 & 378,45 & 135,71 & $-0,66$ & 0,999 \\
\hline 45 & 399,19 & 26,81 & $-0,39$ & 0,969 \\
\hline 50 & 294,93 & 31,07 & $-0,35$ & 0,999 \\
\hline
\end{tabular}

Tabela 7: Parâmetros de ajuste das vigas envelhecidas para as diversas temperaturas.

\begin{tabular}{c|c|c|c|c}
\hline \multirow{2}{*}{ TEMPERATURA $\left({ }^{\circ} \mathbf{C}\right)$} & \multicolumn{4}{|c}{ PARÂMETRO } \\
\cline { 2 - 5 } & $\boldsymbol{\omega 1}$ & $\boldsymbol{\eta}$ & $\boldsymbol{\alpha}$ & $\mathbf{R}^{\mathbf{2}}$ \\
\hline 25 & 286,78 & $2.387,18$ & $-0,90$ & 0,975 \\
\hline 30 & 265,10 & $1.514,77$ & $-0,86$ & 0,962 \\
\hline 35 & 701,16 & 226,53 & $-0,73$ & 0,999 \\
\hline 40 & 745,17 & 121,20 & $-0,66$ & 0,998 \\
\hline
\end{tabular}




\begin{tabular}{c|c|c|c|c}
\hline 45 & 104,06 & $1.156,20$ & $-0,73$ & 0,994 \\
\hline 50 & 99,62 & 877,75 & $-0,69$ & 0,980 \\
\hline
\end{tabular}

Em análise visual complementar, os gráficos das Figuras 13 e 14 permitem concluir que a relação $y_{\max } / F_{\max }$ aumenta com a temperatura e é reduzida à medida em que se acresce a frequência de carregamento, relacionada diretamente com a frequência angular $\omega$. Por outro lado, percebe-se notadamente, a exemplo do que foi apresentado na Figura 11, que mostra a variação de $\left|E^{*}\right|$ com a temperatura, uma tendência de saturação do compósito asfáltico nas duas formulações, evidenciando uma convergência das curvas à medida em que a temperatura aumenta, condição na qual a mistura asfáltica torna-se mais viscosa.

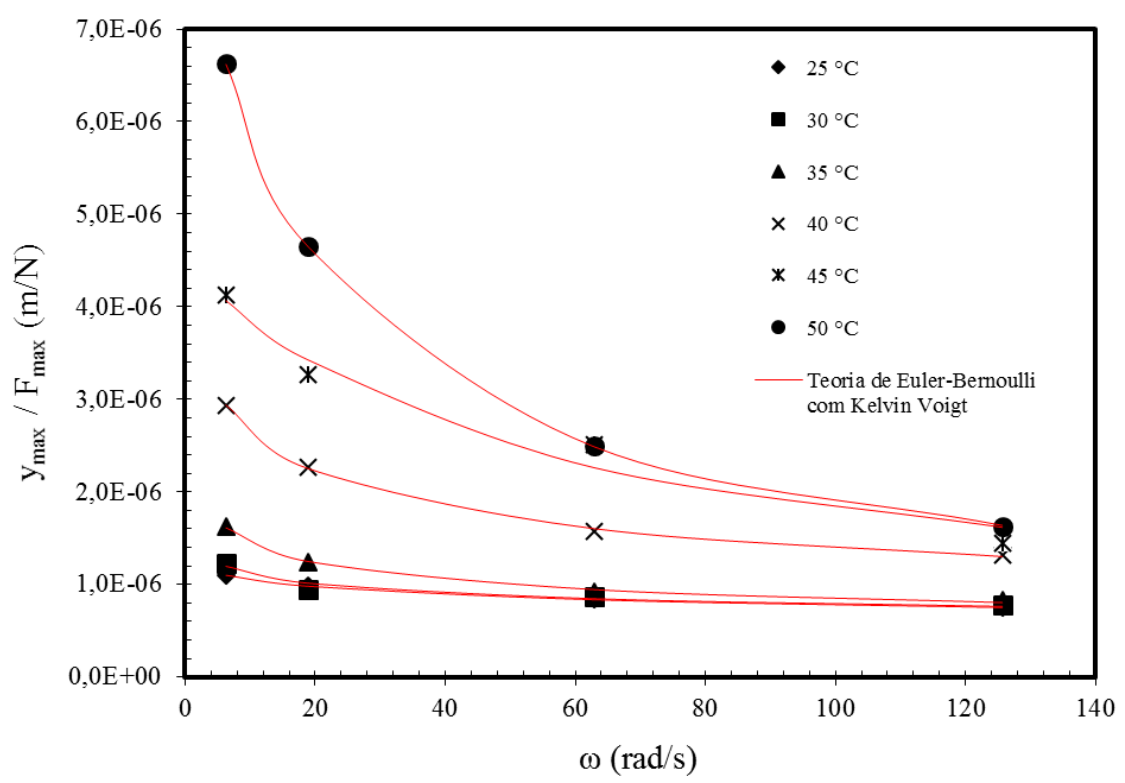

Figura 13: Curva de ajuste teórico da relação $y_{\max } / F_{\max }$ concernente aos dados experimentais registrados para as vigas frescas.

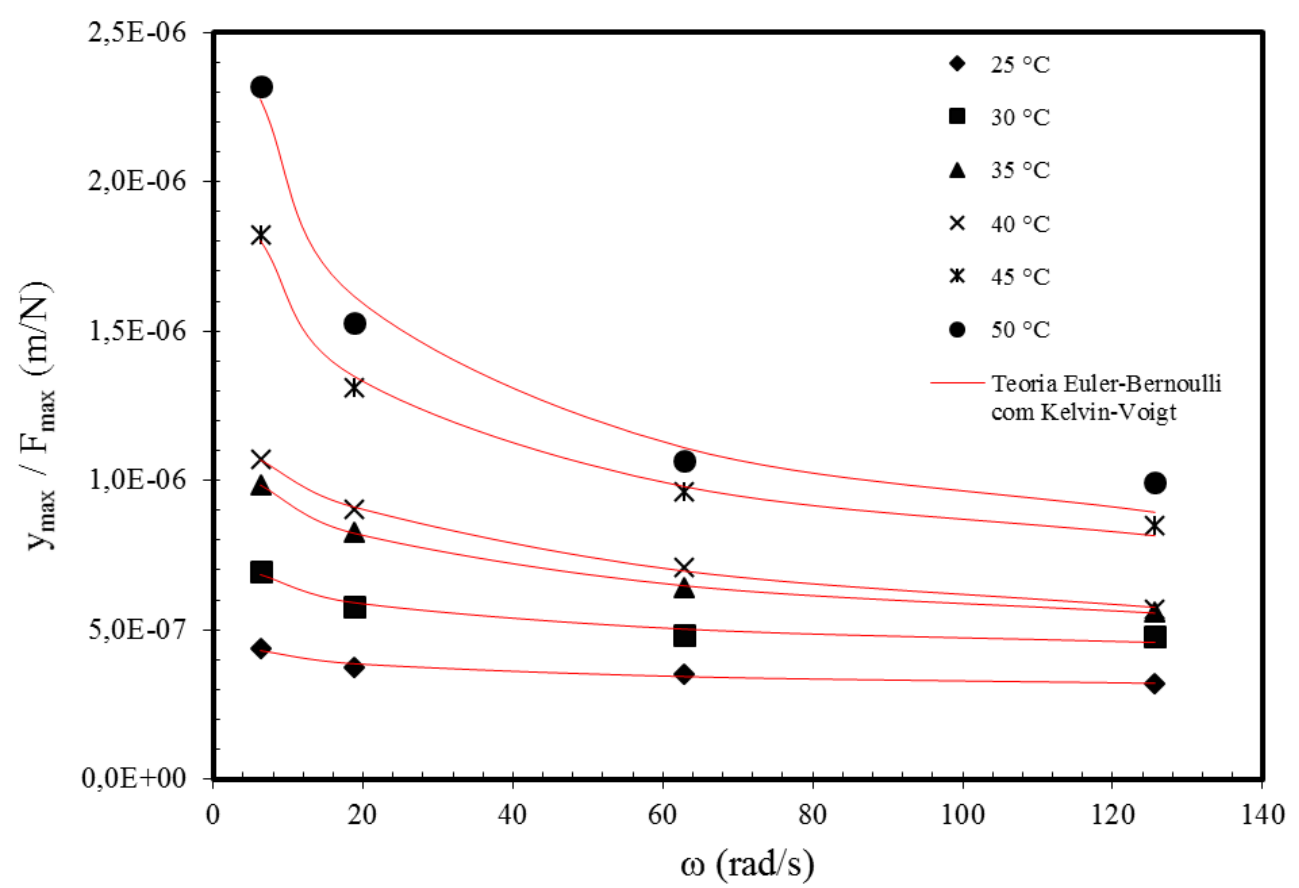

Figura 14: Curva de ajuste teórico da relação $y_{\max } / F_{\max }$ concernente aos dados experimentais registrados para as vigas envelhecidas. 
Nesse sentido, a modelagem teórico-experimental apresenta-se válida para as formulações pesquisadas, mostrando-se adaptável ao efeito do envelhecimento na viscosidade da mistura asfáltica com agregado de argila calcinada, uma vez que os valores atinentes ao parâmetro $\eta_{1}$ foram superiores aos da composição fresca, com exceção daqueles alusivos às temperaturas de 35 e $40{ }^{\circ} \mathrm{C}$, conforme exposto nas Tabelas 6 e 7 , porém com excelentes coeficientes de determinação $\mathrm{R}^{2}$ (0,999 e 0,998, respectivamente). Nesse contexto, as vigas envelhecidas apresentaram uma relação $y_{\max } / F_{\max }$ inferior àquelas das vigas recém-moldadas. Isto se deve ao acréscimo de rigidez alcançado durante o período de cinco anos de envelhecimento das vigotas, permitindo concluir que, para induzir uma determinada amplitude de deslocamento no corpo de prova com maior dureza, o equipamento de flexão a quatro pontos deve aplicar uma carga superior quando comparada com aquela que aplicaria ao corpo de prova no estado fresco. A título ilustrativo, plotou-se o gráfico da Figura 15, onde compara-se a ordem de grandeza referente à relação das amplitudes para ambas as formulações, a $25^{\circ} \mathrm{C}$.

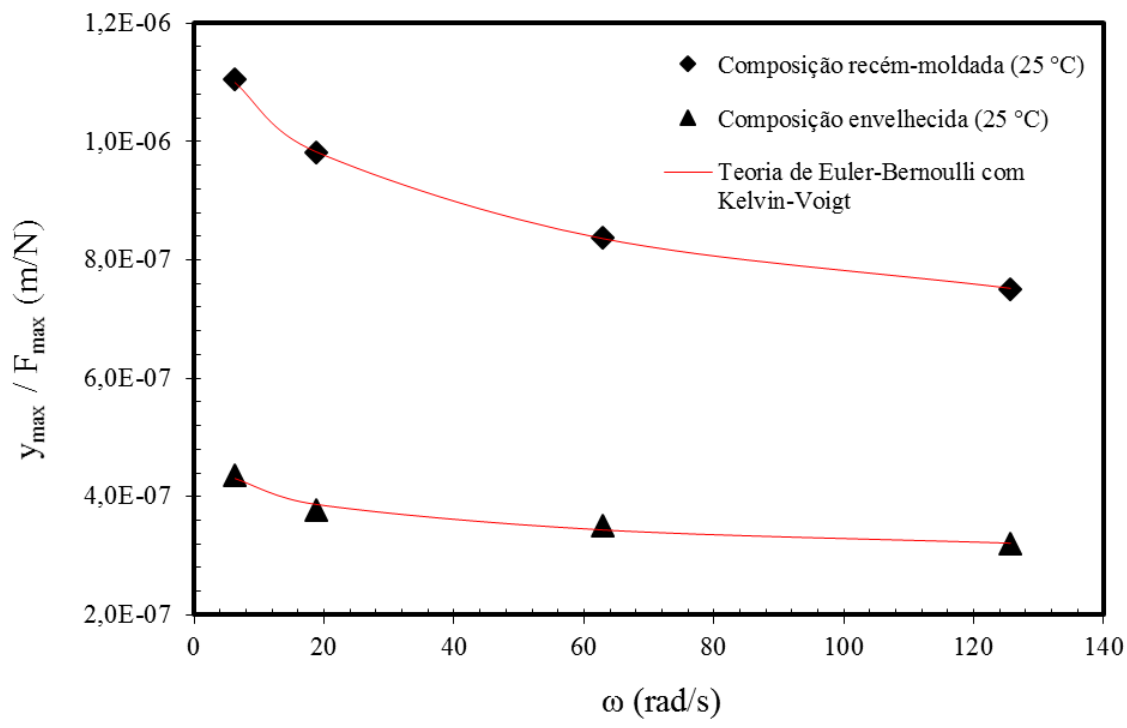

Figura 15: Comparação entre a relação $\mathrm{y}_{\max } / \mathrm{F}_{\max }$ para as composições estudadas a $25^{\circ} \mathrm{C}$.

\section{CONCLUSÕES}

Após a análise das propriedades mecânicas da mistura asfáltica confeccionada com agregado sinterizado de argila calcinada sob flexão a quatro pontos, pode-se destacar as seguintes conclusões:

Constatou-se que o processo de compactação das vigas asfálticas pode exercer influência significativa na magnitude dos valores do módulo de rigidez dinâmico |E*|, possibilitando variação superior a $200 \mathrm{MPa}$.

As deformações permanentes estão diretamente associadas à parcela viscosa do compósito asfáltico, e assim, quando se aumenta a temperatura, maiores são as deformações plásticas, isto é, não recuperáveis. Em virtude disso, o aumento da temperatura até $50^{\circ} \mathrm{C}$, além de diminuir consideravelmente a resistência mecânica das misturas com ASAC, retratada pela redução do módulo dinâmico, torna-o mais suscetível aos defeitos do tipo deformação permanente.

Em decorrência do fenômeno do envelhecimento, que tem início desde o processo de usinagem da massa asfáltica e perdura durante toda a vida de serviço do pavimento, mormente por sua exposição à variação de temperatura e processo de oxidação, acarreta-se o aumento da rigidez da composição, retratada pelo acréscimo do módulo dinâmico $\left|\mathrm{E}^{*}\right|$.

Em face das condições climáticas e de trafegabilidade, a rigidez apresenta variações abruptas nas condições fresca e envelhecida, principalmente na ocasião em que o pavimento sofre rigorosas variações de temperatura. Como exemplo, o módulo dinâmico da formulação envelhecida cai de $2.780,3 \mathrm{MPa}$ a $25{ }^{\circ} \mathrm{C}$, sob frequência de $3 \mathrm{~Hz}$, para $524,7 \mathrm{MPa}$ a $50{ }^{\circ} \mathrm{C}$, quando submetido a frequência de $1 \mathrm{~Hz}$. Essa variação equivale a uma queda de $81,1 \%$;

Os dados resultantes dos experimentos foram registrados com boa precisão, permitindo o êxito do ajuste concernente à modelagem dos parâmetros associados à viscosidade, face aos excelentes coeficientes de determinação $\mathrm{R}^{2}$ encontrados, evidenciando a confiabilidade da Teoria de Euler-Bernoulli com Viscoelasticidade diante da convergência entre as iterações realizadas para as composições frescas e envelhecidas, mostran- 
do-se adaptável ao efeito do envelhecimento na viscosidade da mistura asfáltica com agregado de argila calcinada.

\section{AGRADECIMENTOS}

Ao Conselho Nacional de Desenvolvimento Científico e Tecnológico (CNPq) pela concessão da bolsa ao primeiro autor.

\section{BIBLIOGRAFIA}

[1] FROTA, C.A., SILVA, C.L, NUNES, F.R.G. "Análise do comportamento mecânico de misturas asfálticas confeccionadas com agregados sintéticos de argila calcinada". Anais da V Jornadas Luso-Brasileiras de Pavimentos. Recife, PE, 2006.

[2] SILVA, A.C.L, FROTA, C.A. "Estudo da viabilidade econômica para produção de agregado sinterizado de argila calcinada (Study of economic viability for production of sintered aggregate of calcined clay)." Cerâmica, 59. p. 508-517, 2013.

[3] SILVA, A.C.L. "Comportamento Mecânico de Compósitos Asfálticos com Argila Calcinada sob Flexão a Quatro Pontos". Dissertação de Mestrado, Programa de Pós-Graduação em Engenharia de Recursos da Amazônia - UFAM, Manaus, AM, 2014.

[4] SILVA, A.C.L, FROTA, C.A., FROTA, H.O. (2015a). "Módulo complexo de compósitos asfálticos com argila calcinada sob flexão a quatro pontos (Complex modulus of asphalt mix with calcined clay under fourpoint bending)." Revista Matéria, 20, p. 436-451.

[5] SILVA, C.L., FROTA, H.O., FROTA, C.A. "Sintered calcined clay as an alternative coarse aggregate for asphalt pavement construction". DOI: http://dx.doi.org/10.4236/ojce.2015.53028. Open Journal of Civil Engineering. V. 5, p. 281-288, 2015b.

[6] SILVA, A.C.L., FROTA, C.A. "Análise teórico-experimental do módulo dinâmico de compósitos asfálticos com argila calcinada (Theoretical-experimental analysis of dynamic modulus of asphalt mix with calcined clay)." Cerâmica, v. 62, p. 392-399, 2016.

[7] CABRAL, A.M. "Comportamento Mecânico de Misturas Asfálticas com Agregado Sinterizado de Argila Modificado por Nanomaterial de Multicamadas de Grafeno". Dissertação de Mestrado, Programa de PósGraduação em Ciência e Engenharia de Materiais - UFAM, Manaus, AM, 2017.

[8] CUNHA, M.J.A., SILVA, C.L., LIMA, C.A.P., et al. "Efeito da temperatura no comportamento mecânico de misturas asfálticas com agregados sinterizados de argila calcinada (ASAC) (Effect of temperature on the mechanical behavior of asphalt mixtures with sintered calcined clay aggregate (SCCA))." e-11970, Revista Matéria, v. 23, n.1, 2018

[9] KIM, Y.R., Modeling of Asphalt Concrete, McGraw-Hill Construction. American Society of Civil Engineers, 2009.

[10] SAKHAEIFAR, M.S., KIM, Y.R., KABIR, P.. "New predictive models for the dynamic modulus of hot mix asphalt”. DOI: https://doi.org/10.1016/j.conbuildmat.2014.11.011, Construction and Building Materials, v. 76, p. 221-231, 2015

[11] NOBAKHT, M., SAKHAEIFAR, M.S. "Dynamic modulus and phase angle prediction of laboratory aged asphalt mixtures". DOI: https://doi.org/10.1016/j.conbuildmat.2018.09.160, Construction and Building Materials, v. 190, p. 740-751, 2018

[12] CENTOFANTE, R., SPECHT, L.P., JUNIOR, P.O.B.A., PINHEIRO, R.J.B., PEREIRA, D.S.. "Avaliação do comportamento de misturas asfálticas recicladas a quente com inserção de material fresado (Evaluation of the behavior of hot-recycled asphaltic mixtures with reclaimed asphalt)." Revista Matéria, v. 23, n. 03, 2018.

[13] PETERSEN, J.C. "A review of the fundamentals of asphalt oxidation: chemical, physicochemical, physical property, and durability relationships". Transportation Research E-Circular, 1, Transportation Research Board, 2009.

[14] ANDROJIĆ, I. "Ageing of hot mix asphalt". DOI: https://doi.org/10.14256/JCE.1420.2015. Građevinar v. 68 n. 6, p. 477-483, 2016.

[15] DING, Y., HUANG, B., SHU, X.. "Blending efficiency evaluation of plant asphalt mixtures using fluorescence microscopy”. DOI: https://doi.org/10.1016/j.conbuildmat.2017.11.138. Constr. Build. Mater., v. 161, p. $461-467,2018$ 
[16] SUN, D., SUN, G., ZHU, X., et al.. "Intrinsic temperature sensitive self-healing character of asphalt binders based on molecular dynamics simulations". DOI: https://doi.org/10.1016/j.fuel.2017.09.089. Fuel v. 211, p. 609-620, 2018.

[17] DI BENEDETTO, H., PARTL, M.N., FRANCKEN, L., et al. Stiffness testing for bituminous mixtures, Mater. Struct. V. 34 , pp. 66-70, 2001.

[18] KING, M. H. "Determination of Dynamic Moduli in Uniaxial Compression for North Caroline Hot Mix Asphalt Concrete". Master Thesis, North Carolina State University, Raleigh, NC, 2004.

[19] PELLINEN, T, CROCKFORD, B. "Comparison of analysis techniques to obtain modulus and phase angle from sinusoidal test data". In: Sixth International RILEM Symposium on Performance Testing and Evaluation of Bituminous Materials. RILEM Publications SARL, pp. 301-307, 2003.

[20] MORENO-NAVARRO, F., SOL-SÁNCHEZ, M., GARCÍA-TRAVÉ, G., et al. "Fatigue cracking in asphalt mixtures: the effects of ageing and temperature", DOI: 10.1080/14680629.2018.1418717, Road Materials and Pavement Design, 2017

[21] SARSAM, S.I., ADBULMAJEED, S.M. "Influence of Aging Time on Asphalt Pavement Performance". Journal of Engineering, v. 20, n. 12, p. 12, 2014

[22] SIRIN, O., PAUL, D.K., KASSEM, E. "State of the Art Study on Aging of Asphalt Mixtures and Use of Antioxidants Additives". DOI: https://doi.org/10.1155/2018/3428961, Advances in Civil Engineering, v. 2018, pp. 1-19.

[23] LOLLY, R. "Evaluation of Short Term Aging Effect of Hot Mix asphalt Due to Elevated Temperatures and Extended Aging Time", Arizona State University, 2013.

[24] CUI, P.Q., ZHANG, H.H., WU, S.P. "Influence of High-Temperature Volatilization on Performance of Bituminous Binder”, DOI: http://dx.doi.org/10.4028/www.scientific.net/KEM.599.164. Key Engineering Materials, v. 599, pp. 164-167, 2014.

[25] WEN, Y., WANG, Y. "Effect of oxidative aging on dynamic modulus of hot-mix asphalt mixtures.", DOI: 10.1061/ (ASCE) MT.1943-5533.0002547. 04018348. J. Mater. Civ. Eng. v. 31, n. 1, 2019

[26] COMITÊ EUROPEU DE NORMALIZAÇÃO - CEN. "EN 12697-24. "Bituminous mixtures. Test methods for hot mix asphalt, Part 24: Resistance to fatigue”. Bruxelas. 2004.

[27] PICANÇO, H.M., CARTAXO, E.F., FROTA, C.A., et al."Refletividade, Radiação Solar e Temperatura em Diferentes Tipos de Revestimentos das Vias Urbanas no Município de Manaus (AM)." $5^{\circ}$ Congresso de Infraestrutura de Transportes. São Paulo, 2011.

[28] MELO, J.V.S., TRICHÊS, G., ROSSO, L.T. "Experimental evaluation of the influence of reinforcement with Multi-Walled Carbon Nanotubes (MWCNTs) on the properties and fatigue life of hot mix asphalt." Construction and Building Materials, 162, 369-382, 2018.

[29] DI BENEDETTO, H., LA ROCHE, C., BAAJ, H., et al.. "Fatigue of bituminous mixtures". DOI: 10.1007/bf02481620. Materials and Structures, v. 37, n. 3, p. 202-216. 2004

[30] MASSON, J.F., COLLINS, P., POLOMARK, G. "Steric hardening and the ordering of asphaltenes in bitumen." Energy and Fuels, v. 19, n. 1, pp. 120-122, 2005.

[31] READ, J., WHITEOAK, D. The Shell Bitumen handbook (5th ed.). London: Thomas Telford Publishing, Shell Bitumen UK, 2003.

[32] ABU AL-RUB, R., DARABI, M., KIM, S., et al. "Mechanistic-based constitutive modeling of oxidative ageing in ageing susceptible materials and its effect on the damage potential of asphalt concrete. Construction and Building Materials, v. 41, p. 439-454, 2013.

[33] HUANG, Y.H. Pavement analysis and design. Englewood Cliffs, N.J.: Prentice Hall, 1993, 805p.

\section{ORCID}

Juliano Rodrigues Spínola

Antônio Cleiton Lopes da Silva

Consuelo Alves da Frota

Hidembergue Ordozgoith da Frota https://orcid.org/0000-0001-8034-0619

https://orcid.org/0000-0001-7343-350X

https://orcid.org/0000-0002-1766-2823

https://orcid.org/0000-0002-2178-185X 